\title{
Variations and Control of Thrust and Mixture Ratio in Hybrid Rocket Motors
}

\author{
Francesco Barato $^{1}\left(\mathbb{0} \cdot\right.$ Elena Toson $^{2} \cdot$ Daniele Pavarin $^{1,2}$
}

Received: 31 August 2020 / Revised: 28 March 2021 / Accepted: 29 March 2021 / Published online: 18 April 2021

(c) The Author(s) 2021

\begin{abstract}
Hybrid rocket motors have several attracting characteristics such as simplicity, low cost, safety, reliability, environmental friendliness. In particular, hybrid rockets can provide complex and flexible thrust profiles not possible with solid rockets in a simpler way than liquid rockets, controlling only a single fluid. Unfortunately, the drawback of this feature is that the mixture ratio cannot be directly controlled but depends on the specific regression rate law. Therefore, in the general case the mixture ratio changes with time and with throttling. Thrust could also change with time for a fixed oxidizer flow. Moreover, propellant residuals are generated by the mixture ratio shift if the throttling profile is not known in advance. The penalties incurred could be more or less significant depending on the mission profile and requirements. In this paper, some proposed ways to mitigate or eliminate these issues are recalled, quantitatively analysed and compared with the standard case. In particular, the addition of energetic additives to influence the regression rate law, the injection of oxidizer in the post-chamber and the altering-intensity swirling-oxidizer-flow injection are discussed. The first option exploits the pressure dependency of the fuel regression to mitigate the shift during throttling. The other two techniques can control both the mixture ratio and thrust, at least in a certain range, at the expense of an increase of the architecture complexity. Moreover, some other options like pulse width modulation or multi-chamber configuration are also presented. Finally, a review of the techniques to achieve high throttling ratios keeping motor stability and efficiency is also discussed.
\end{abstract}

Keywords Hybrid rockets $\cdot$ Throttling $\cdot$ Mixture ratio control $\cdot$ Penalties $\cdot$ Residuals

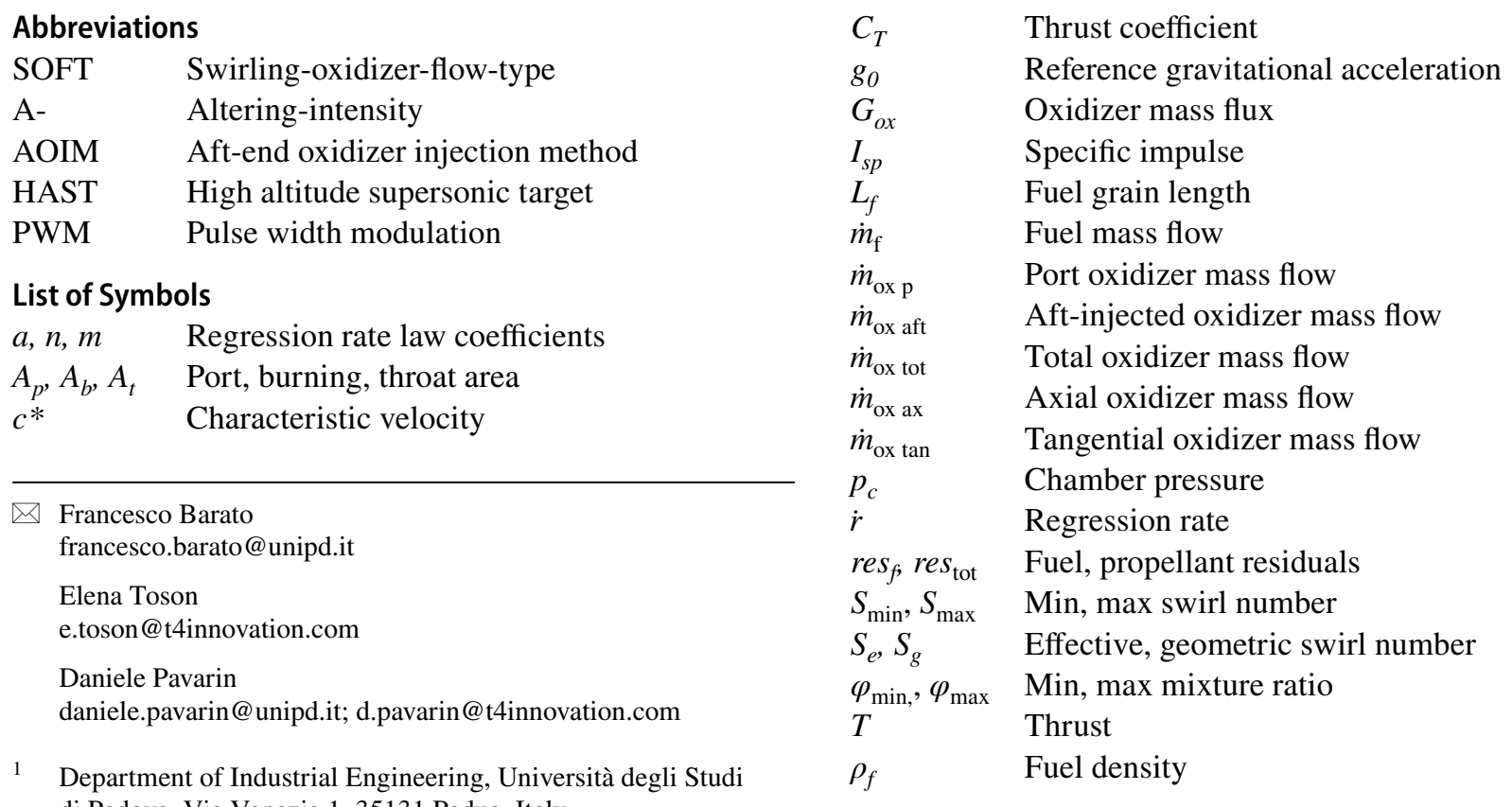




\section{Introduction}

Hybrid rockets have been studied since the '30s or the thirties but have never come into fruition and their research has been limited compared to the commonly employed solid and liquid technologies [1-6]. Nowadays, a shift of focus from pure performance to a broader range of aspects including simplicity, reliability, cost, safety, flexibility, ease-of-use/production, environmental friendliness, has recently brought a renewed interest toward hybrid propulsion, which potentially bring several advantages compared to traditional liquid and solid propulsion [7]. In particular, one often claimed advantage of hybrid propulsion is to guarantee a similar level of energy management of a liquid rocket like deep throttling and multiple stop-restart on demand, which is much higher than commonly possible with solids, together with a significantly reduced complexity and improved safety compared to liquids [8].

Several demonstrations of this capability have been performed along the years, starting from Moore [9], continuing with the work at UTC related to target drones and upper stages [10-12], followed by AMROC experience [13-18] and several NASA-related programs [19-22]. A more detailed summary of hybrid rocket throttling history is given by Peterson [23, 24].

Recently, remarkable demonstrations have been performed by Purdue [25], USU [23, 24], NAMMO [26, 27] and UNIPD [28-32]. Moreover, a program for a Mars softlander demonstrator based on hybrid propulsion has been funded by the European community [33-36].

Overall, throttling ratio as high as 10:1 have been successfully achieved keeping high levels of combustion stability and efficiency.

However, a well-known negative peculiarity of hybrid rockets is the shift of mixture ratio with time and throttling. This is in contrast with liquids, where both propellants mass flows are controlled, and solids, where the mixture ratio is defined in the propellant grain casting process. On the contrary, the specific hybrid rocket behaviour is related to the fact that only the oxidizer flow is controlled and the regression of the fuel follows a non-linear dependency on the oxidizer flux:

$\dot{m}_{f}=\rho_{f} \dot{r} A_{b}=\rho_{f} a G_{o x}^{n} p_{c}^{m} A_{b}$

which, in turn, varies also with the port area:

$G_{o x}=\dot{m}_{\text {oxp }} / A_{p}$

The chamber pressure and the mixture ratio are thus determined by the imposed oxidizer mass flow and the corresponding indirectly obtained fuel mass flow: $\left(\dot{m}_{\text {oxtot }}+\dot{m}_{f}\right) c^{*}=p_{c} A_{t}$

$\varphi=\dot{m}_{\text {oxtot }} / \dot{m}_{f}$

Several ideas have been proposed to be able to control the mixture ratio both in time and during throttling, like the addition of an aft-injection of further oxidizer, called AOIM $[2,37]$, and the recently proposed Altering-intensity Swirling Oxidizer Flow Type (A-SOFT) configuration by Shimada et al. [38-43], see Fig. 1.

The objective of this paper is to recall and revaluate all the main techniques to control hybrid rockets mixture ratio and compare them to classical hybrid behaviour.

The paper is organised in the following way. In the second chapter the classical behaviour including a pressure dependency is considered and the penalties related to throttling are evaluated. In the third chapter the AOIM technique is analysed. In the fourth chapter the A-SOFT is investigated. The two techniques are then compared in chapter five. In the sixth chapter other options are briefly discussed. Finally, a review of the techniques to achieve high throttling ratios keeping motor stability and efficiency is also presented.

\section{Classical Behaviour and Penalties Evaluation}

It is well-known that in a classical hybrid rocket the mixture ratio varies with time and throttling, as described in $[6,44]$. For a constant oxidizer flow and a cylindrical port, if the regression rate exponent is 0.5 the mixture ratio is constant with time, if it is higher the mixture ratio increases, while the opposite occurs for lower values. For non-cylindrical port typically used in wagon wheel multiport grains like triangular or trapezoidal, the neutral point shifts below 0.5. For the extreme case of a constant burning area grain like some

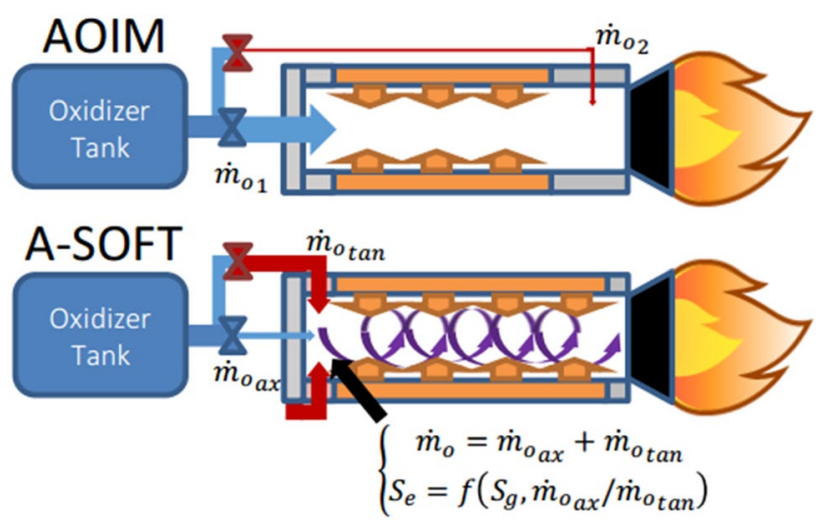

Fig. 1 AOIM and A-SOFT configurations. Figure taken from Ozawa and Shimada [43] 
star's shapes used in solid propulsion for neutral burning, the neutral point is $n=0$ and the hybrid thrust behaviour is always regressive.

In case of throttling, if $n$ is equal to one no mixture ratio shift occurs, while for lower values typical of hybrids, the fuel mass flow variation with the oxidizer is sublinear. However, as shown in [28], while a value of $n$ equal to one guarantees no direct penalties, a value of $n$ equal to 0.5 can be favourable also for throttling as performance, particularly the thrust level, become independent from the throttling history. In [44] it was demonstrated that throttling down from the optimal point provides the most linear behaviour. Moreover, for the same time spent at a certain throttle level, the maximum amount of total impulse is generated at maximum thrust, so it makes sense to have the optimal point there. Anyway, the real optimal solution should take into account the expected/required thrust profile with time.

It is important to highlight that the relation between thrust and mixture ratio variations during time has the opposite trend respect to the case of throttling, so compensating the thrust variation with time trough throttling has the consequence to exacerbate the mixture ratio shift with time [23, 24].

In case of a pressure dependency $m$ of the fuel regression rate, for example trough the addition of energetic additives to the fuel, the mixture ratio shift with time follows the same trend as before with $n=0.5$ as neutral point but the results get slightly worse as shown in Fig. 2, which has been obtained using (1), (2), (3) and (4) only changing the port area considering a cylindrical port. In fact, the reduction or increment of fuel induces a corresponding reduction or increment of pressure that in turn decreases or increases further, respectively, the regression rate.

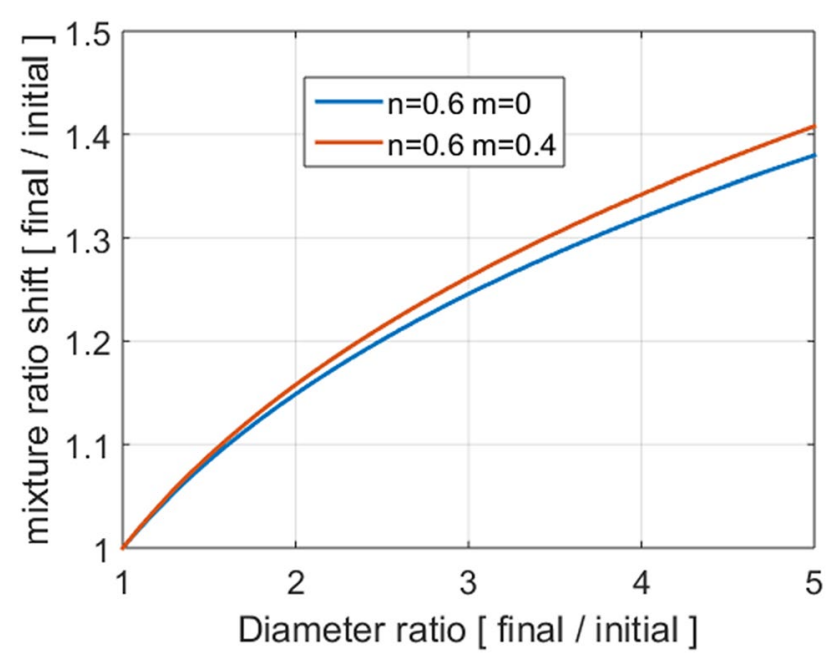

Fig. 2 Mixture ratio shift with time
On the contrary, the mixture ratio shift with throttling is mitigated by the pressure dependency as the new neutral point is now defined by the sum of the two exponents $n+m$ being equal to 1 [2]. An example is shown in Figs. 3 and 4, which have been obtained again using (1), (2), (3) and (4), this time only changing the oxidizer flow at a constant port area.

The characteristic velocity curves obtained from a thermochemical code [45] refers to $90 \%$ hydrogen peroxide and polyethylene and the starting point is set at the optimum mixture ratio.

Slightly different results are obtained with other propellant combinations for the same regression rate laws. However, it is important to note that any propellant combination will have not only its own $c^{*}$ curve but also regression rate

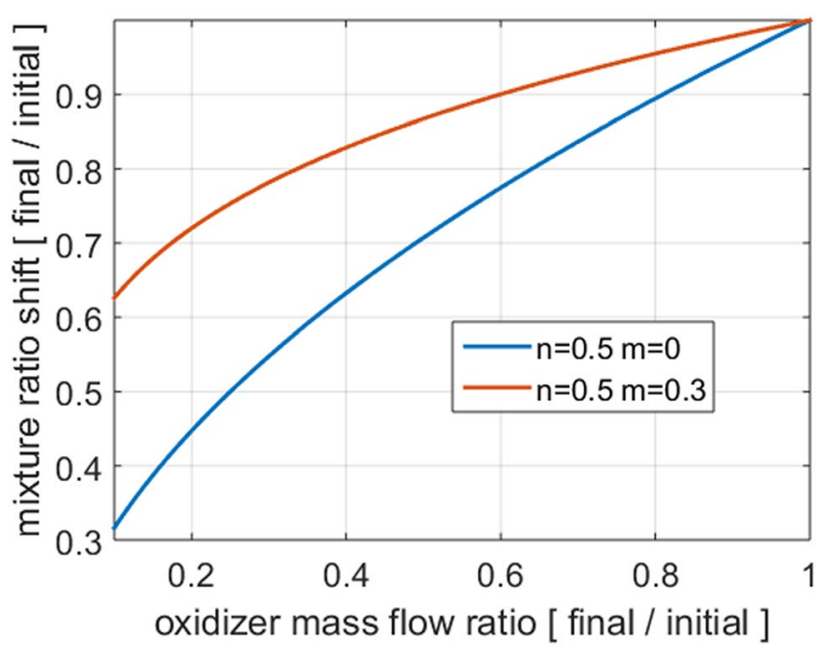

Fig. 3 Mixture ratio shift with throttling

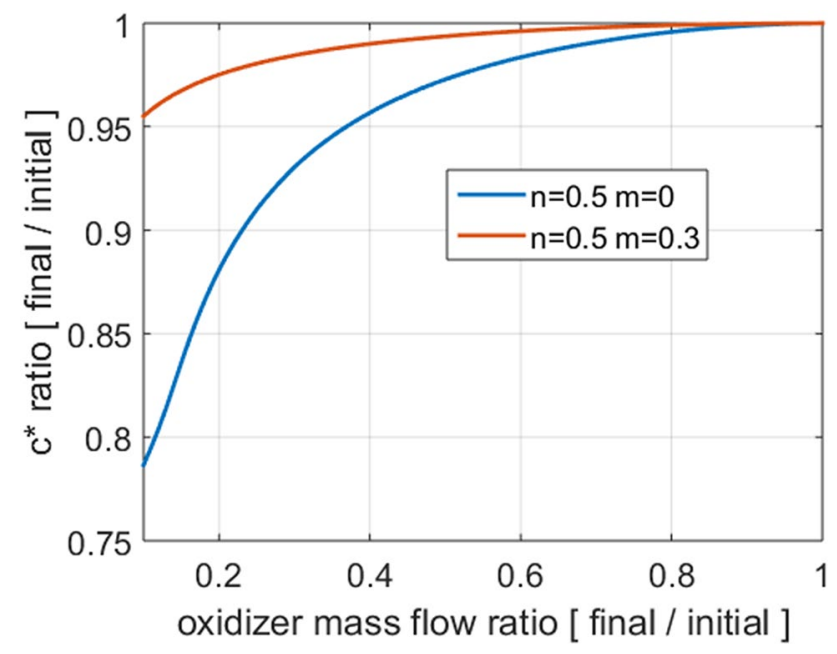

Fig. 4 Characteristic velocity with throttling. Initial chamber pressure: 50 bar 
exponents $n$ and $m$, so the real results have to be calculated case by case. Often, adding energetic additives has the effect to reduce $n$ and increase $m$.

In theory, the "perfect" regression rate law, with the mixture ratio insensitive to both time and throttling, will require both exponents equal to 0.5 , this has not been obtained in practice yet.

In general, adding metals in the hybrid fuel has a twofold benefit other than on the energetic content: a reduction of the mixture ratio shift with throttling because of the pressure dependency and a lower sensitivity of $c^{*}$ to the mixture ratio [46], both keeping the specific impulse nearer to its optimum value.

However, as a drawback, with the pressure dependency the mixture ratio becomes dependent on nozzle erosion. Moreover, in general, adding energetic additives to the fuel has the effect to decrease the optimum mixture ratio, exacerbating the sensitivity to the issue of fuel residuals as the fuel mass becomes a higher fraction of the total propellant mass.

When throttling down a conventional motor with a fixed nozzle throat there is a reduction in chamber pressure. Chamber pressure has a second order effect on $c^{*}$ except for very low values but could have a significant impact on the thrust coefficient during atmospheric flight. This penalty is shared also by liquid rockets and by hybrid rockets with mixture ratio control features.

It is interesting to determine the total specific impulse losses during throttling in atmospheric flight. As an example, a non-throttleable motor against a motor with a mass flow throttling ratio of 5 is considered. The nozzle is adapted to an altitude around $7.8 \mathrm{~km}$ to avoid separation at sea level. In case of the throttleable motor the adaptation considers the minimum thrust, thus the nozzle expansion ratio is slightly smaller. Two cases are considered: one with a classical hybrid with $n=0.5$ and the other without mixture ratio shift. For the classical hybrid, the throttling ratio is referred to the oxidizer mass flow. The optimum mixture ratio is set at maximum thrust. The results are presented in Figs. 5, 6, $7,8,9,10$.

The thrust and specific impulse have been calculated with the classical equations:

$T=p_{c} A_{t} C_{T}$

$I_{s p}=c^{*} C_{T} / g_{0}$

where the thrust coefficient is calculated with the selected expansion ratio, the exhaust specific heat ratio and the calculated ratio between chamber pressure and the ambient pressure, which is a function of the altitude. For the classical hybrid, again, (1), (2), (3) and (4) are used, while for the constant mixture ratio case only (3) is used as $\varphi$ is fixed. For

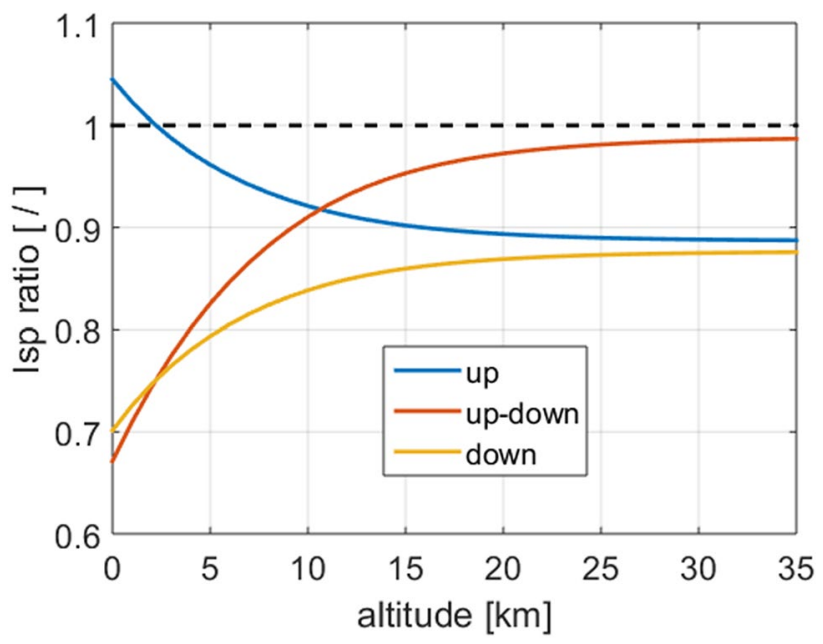

Fig. 5 Specific impulse penalty of a throttleable motor with altitude without mixture ratio shift. Max chamber pressure: 25 bar

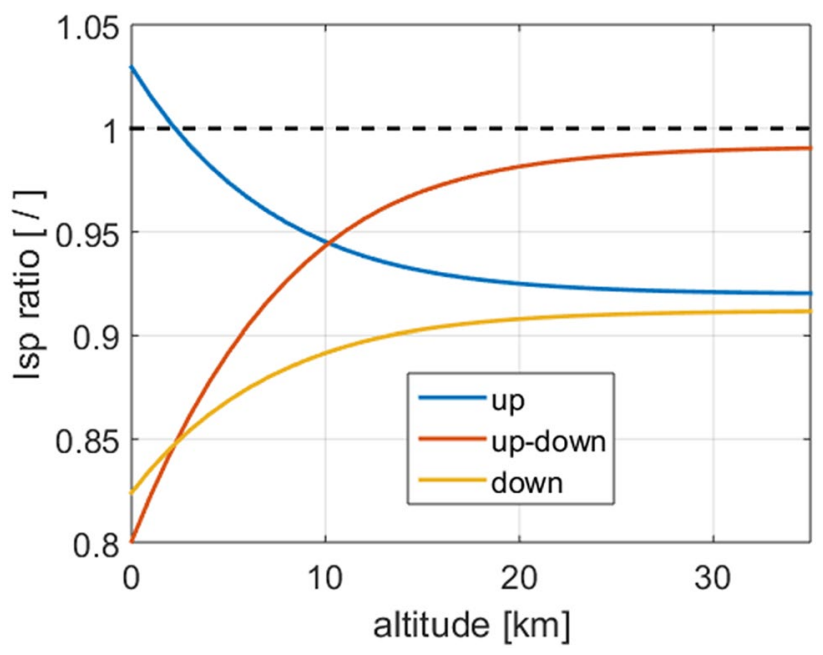

Fig. 6 Specific impulse penalty of a throttleable motor with altitude without mixture ratio shift. Max chamber pressure: 100 bar

the throttleable case, the maximum mass flow is the same as the one of the non-throttleable motor.

In Fig. 5 and the followings up refers to the ratio of the specific impulse of the throttleable case at maximum thrust to the non-throttleable case.

The up-down refers to the ratio of the specific impulse of the throttleable case at maximum thrust to that at minimum thrust.

The down curve refers to the ratio of the specific impulse of the throttleable case at minimum thrust to the non-throttleable case.

As the maximum thrust is selected at the optimum mixture ratio, the specific impulse losses ( $u p$ ) between the throttleable and non-throttleable cases are related only to 


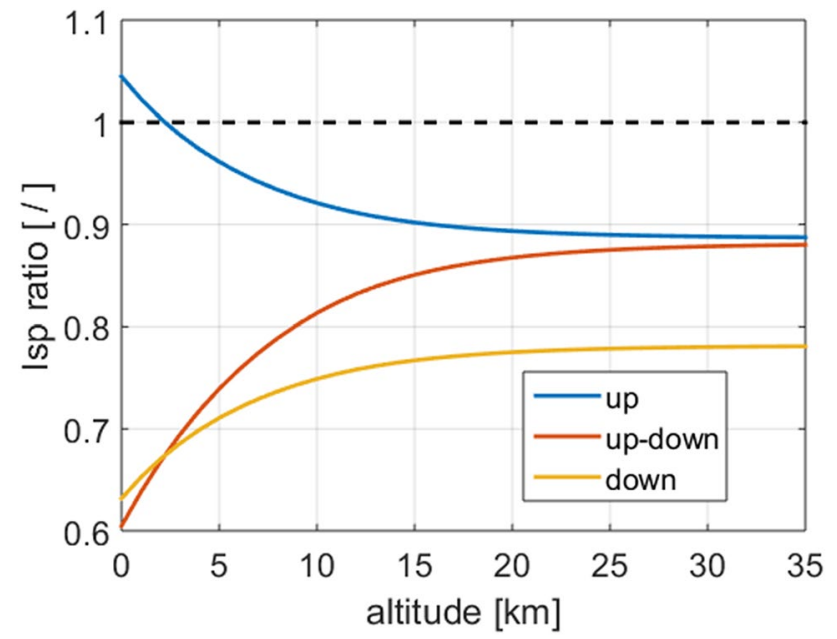

Fig. 7 Specific impulse penalty of a throttleable motor with altitude with mixture ratio shift, $n=0.5$. Max chamber pressure: 25 bar

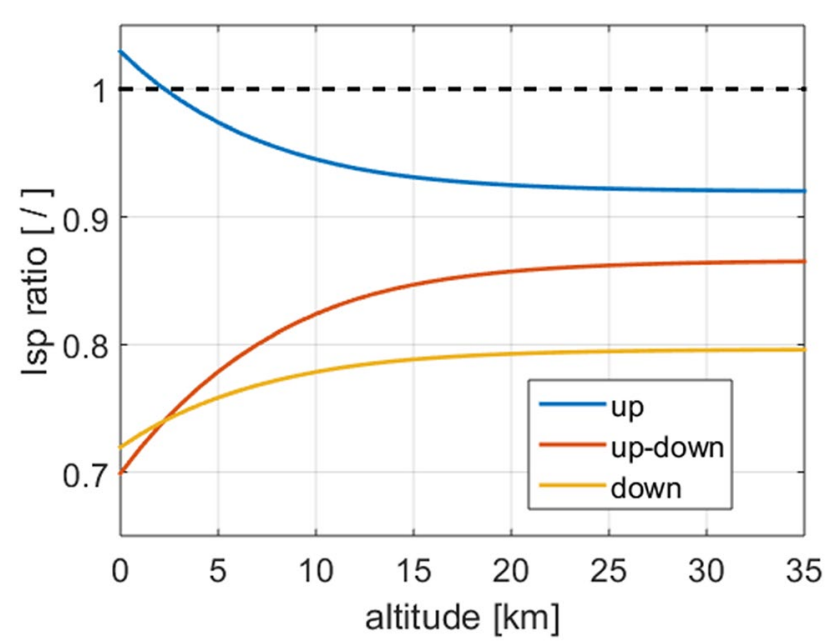

Fig. 8 Specific impulse penalty of a throttleable motor with altitude with mixture ratio shift, $n=0.5$. Max chamber pressure: 100 bar

the lower expansion ratio, which is sized for the minimum thrust. The lower expansion ratio provides a slight advantage at very low altitudes where the larger nozzle is over-expanded.

The ratio (up-down) between the specific impulse at maximum thrust and minimum thrust is determined by the variation of the thrust coefficient with pressure for both cases plus the $c^{*}$ penalty mainly for the case with mixture ratio shift. As expected, the ratio tends almost to unity at high altitudes where the back pressure is negligible for the case with mixture ratio control. A slight penalty is present due to the variation of $c^{*}$ with pressure. In the other case the mixture ratio becomes fuel rich and the specific impulse at minimum thrust is reduced.

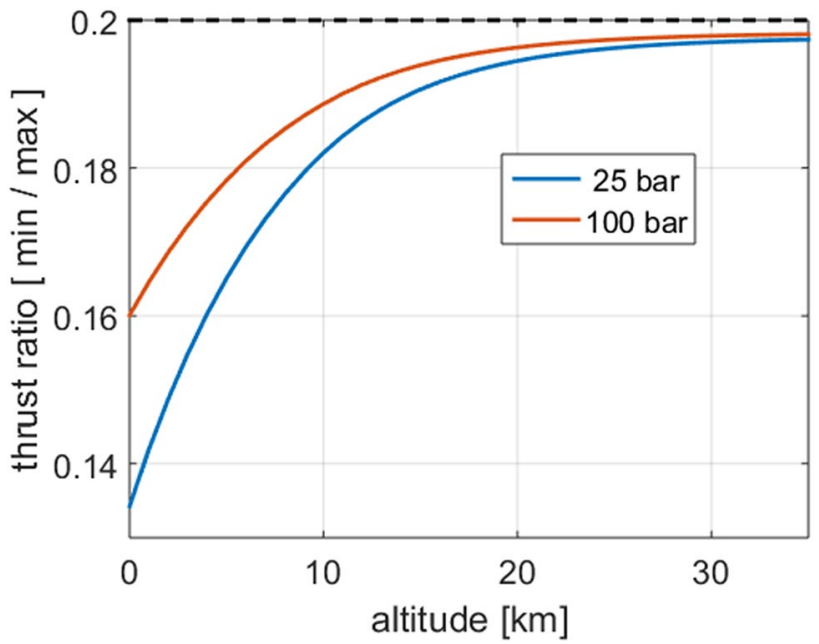

Fig. 9 Thrust ratio of a throttleable motor (5:1) with altitude without mixture ratio shift

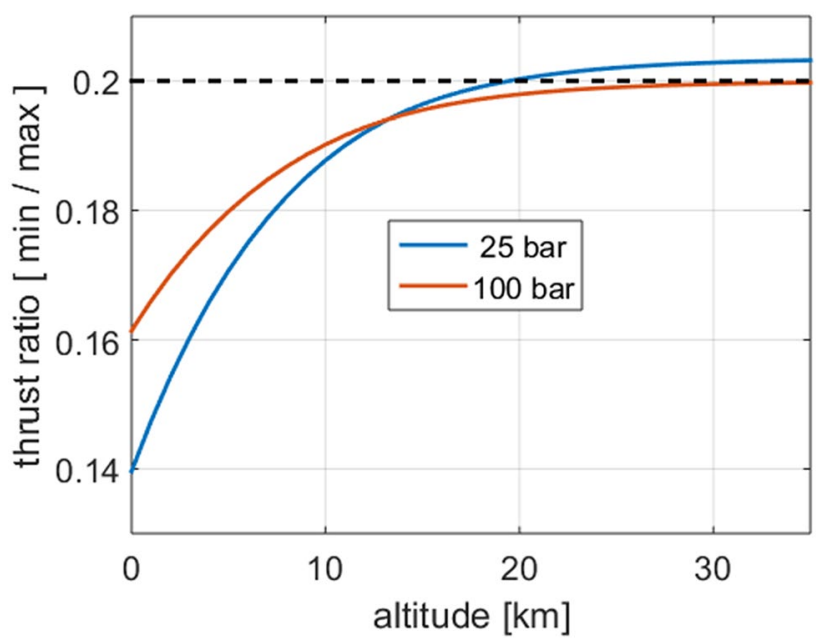

Fig. 10 Thrust ratio of a throttleable motor (5:1) with altitude with mixture ratio shift, $n=0.5$

The total penalty during throttling (down) is due to the lower nozzle expansion ratio (penalty $u p$ ) combined with the lower pressure ratio and eventual mixture ratio shift (penalty up-down).

As maximum chamber pressure is increased the penalty related to the thrust coefficient is reduced. Therefore, the relative impact of the mixture ratio shift is lower at lower pressures. Considering that in general a motor operating at low pressures is simpler and cheaper, mitigating the mixture ratio shift with added complexity for throttleable motors is more indicated for high performing motors operating at high pressures. Moreover, because high throttling ratios mean lower minimum pressures and higher mixture ratio shifts, again the combination high pressure-mixture ratio control is more interesting for very high throttling ratios. In several 
ways, a mixture ratio-controlled hybrid rocket is in-between a classical hybrid and a liquid.

The ratio between the maximum and minimum thrust is higher than the variation of the oxidizer mass flow, mainly due to the effect of the thrust coefficient, see Figs. 9, 10. As the back pressure is reduced with altitude the thrust ratio approaches the oxidizer mass flow ratio except for the effect of the mixture ratio shift and a smaller effect of chamber pressure variation. The global effect is more pronounced for low initial chamber pressures.

The previous analyses could vaguely represent a rocket motor that has to perform a sort of propulsive re-entry/ landing.

In case of a booster during ascent it is interesting to calculate the specific impulse and the maximum throttling ratio of a throttleable motor using the same nozzle of a non-throttleable motor. In this case the throttling ratio is determined by separation of the flow on the over-expanded nozzle. The results for the case with constant mixture ratio are shown in Figs. 11, 12, 13, while those for the case of a classical hybrid with $n=0.5$ are shown in Figs. 14, 15, 16. The same equations as before have been used.

With the constraint of a nozzle adapted for maximum thrust no throttling is possible at sea level.

As the altitude increases and the back pressure decreases the minimum chamber pressure and consequently the thrust can be safely reduced, see Figs. 11 and 14, where the minimum thrust at which the nozzle incur in separation of the flow is plotted.

In Figs. 12 and 15 the thrust with altitude for different oxidizer throttling levels is plotted. The intersection of each curve with the envelope curve determines the minimum altitude where the corresponding level of throttling can occur.

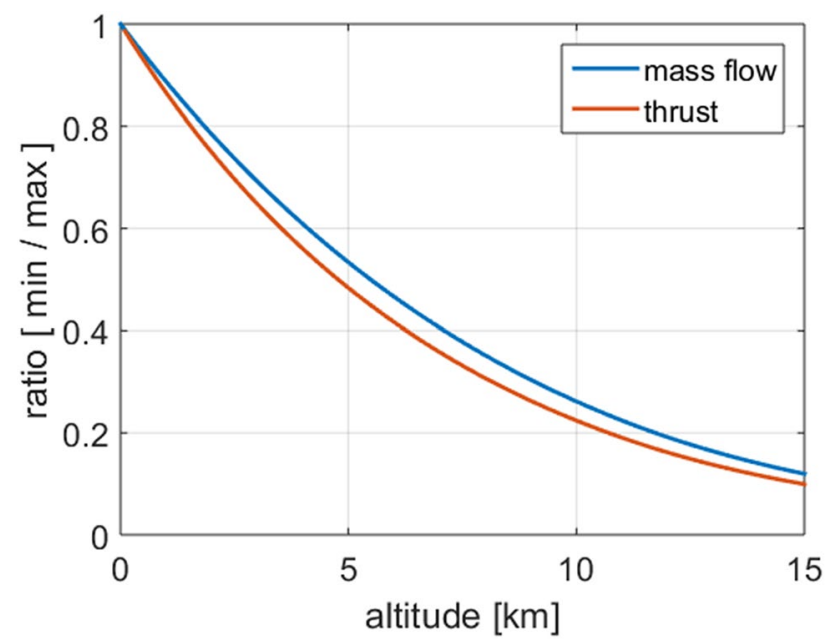

Fig. 11 Minimum thrust with altitude of a throttleable motor with the same nozzle as a non-throttleable one. Constant mixture ratio. Initial chamber pressure: 50 bar

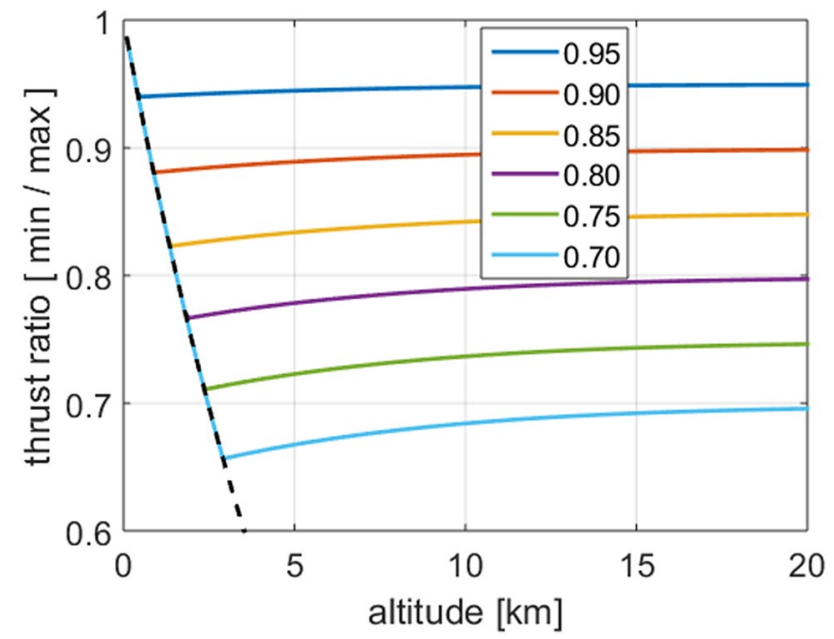

Fig. 12 Thrust with altitude of a throttleable motor. Constant mixture ratio. Parametric with throttling ratio. Initial chamber pressure: 50 bar

In Figs. 13 and 16 the specific impulse with altitude for different oxidizer throttling levels is plotted. Again, the intersection of each curve with the envelope curve determines the minimum altitude where the corresponding level of throttling can occur.

It is possible to see that, unless the initial chamber pressure is too low, a typical throttling down at altitude to limit the maximum dynamic pressure, for example $10-15 \mathrm{~km}$ for common launchers, induces only a small penalty on the thrust coefficient. In this case of limited throttling, also the penalty related to the mixture ratio shift is relatively small, so the usefulness of the added complexity of a mixture ratio control is debatable.

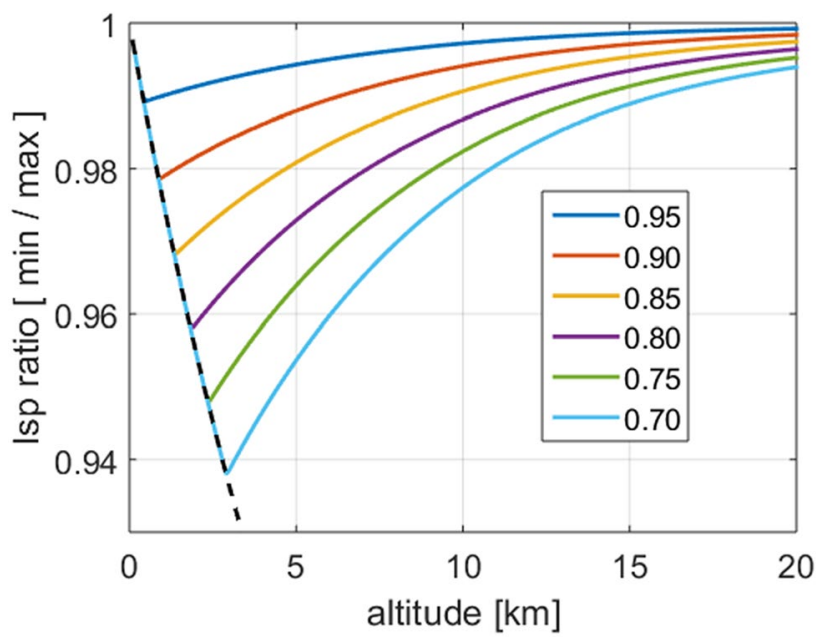

Fig. 13 Specific impulse with altitude of a throttleable motor. Constant mixture ratio. Parametric with throttling ratio. Initial chamber pressure: 50 bar 


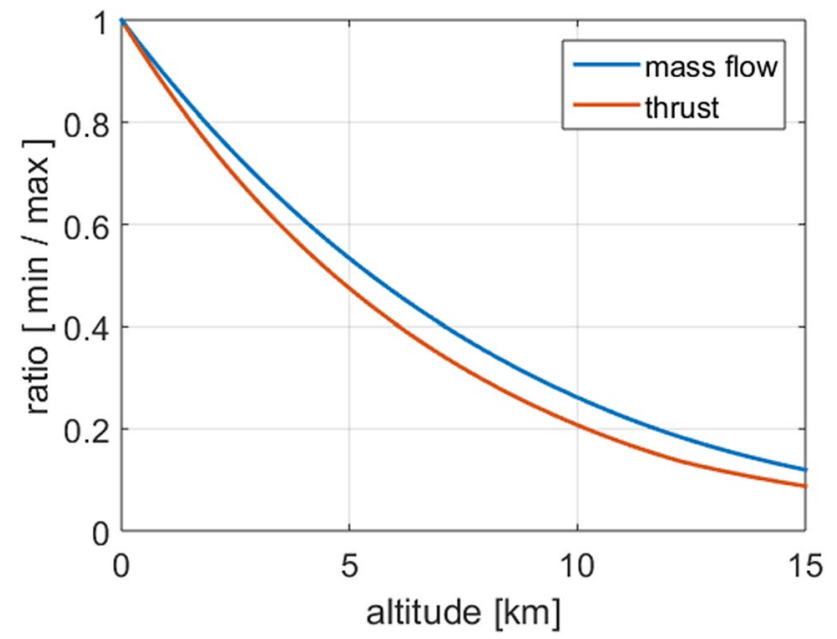

Fig. 14 Minimum thrust with altitude of a throttleable motor with the same nozzle as a non-throttleable one. Hybrid with $n=0.5$. Initial chamber pressure: 50 bar

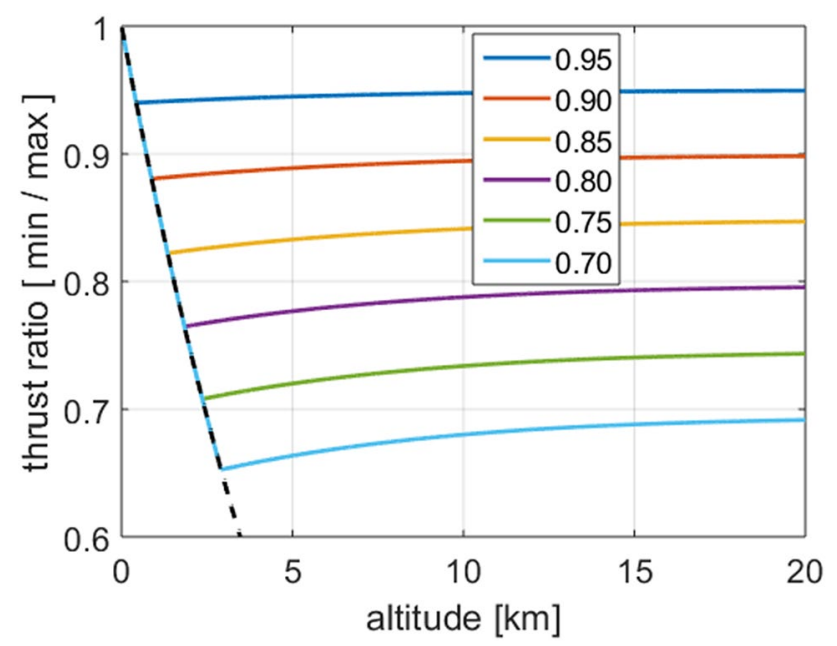

Fig. 15 Thrust with altitude of a throttleable motor. Hybrid with $n=0.5$. Parametric with throttling ratio. Initial chamber pressure: 50 bar

The mixture ratio shift has a significant impact on several aspects: not only a penalty on the specific impulse but also a change in the exhaust characteristics, affecting nozzle erosion and the plume behaviour with consequences on heat transfer, signature, spacecraft contamination, air pollution and so forth.

Moreover, if the required thrust profile is not known in advance, a non-predicted mixture ratio shift will leave propellant residuals. The total impulse and $\Delta V$ penalties from residuals generation can become much larger than the one related to the specific impulse losses if the foreseen thrust profile could have unexpected large variations.

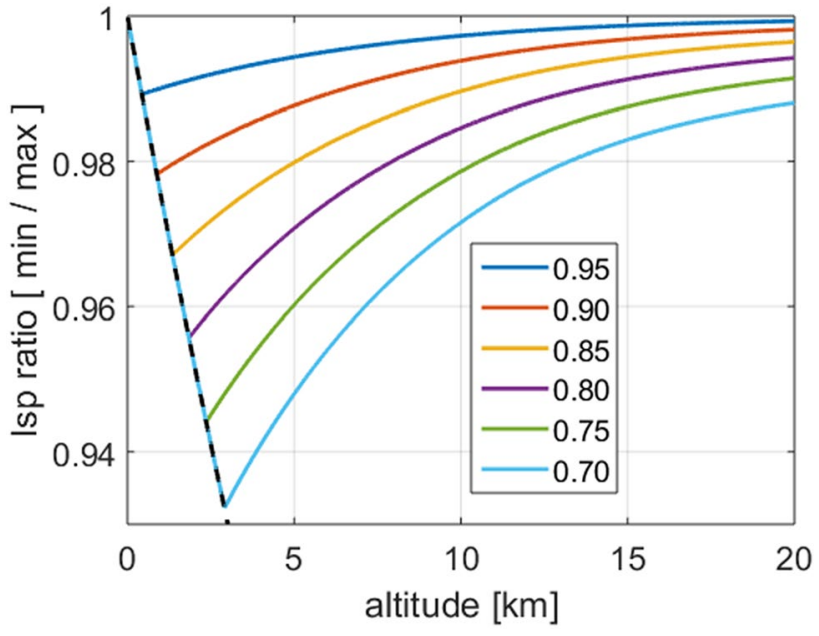

Fig. 16 Specific impulse with altitude of a throttleable motor. Hybrid with $n=0.5$. Parametric with throttling ratio. Initial chamber pressure: 50 bar

The worst case for a defined throttling level capability is to consider that the motor could possibly operate the whole burning time both at maximum or minimum thrust. For the typical high optimal mixture ratio occurring in hybrid propulsion the best residuals mitigation is to design the system to always consume all the oxidizer and to have a fuel margin for any situation [47]. Therefore, the design mixture ratio should be the minimum one, which is reached at minimum thrust. Thus, no residuals are obtained at minimum thrust, while the maximum amount of fuel residuals is generated at maximum thrust and its relative value is:

$r e s_{f}=1-\left(\frac{\varphi_{\min }}{\varphi_{\max }}\right)=1-\left(\frac{\dot{m}_{\text {oxmin }}}{\dot{m}_{\text {oxmax }}}\right)^{1-n}$

where $r e s_{f}$ is the ratio between the fuel residual mass and the initial fuel mass, $\varphi_{\min }\left(\varphi_{\max }\right)$ and $m_{o x}^{\cdot}$ min $\left(m_{o x \max }^{\cdot}\right)$ are the mixture ratio and the oxidizer mass flow at minimum (maximum) thrust, respectively. The last part in (7) is valid in case of no pressure dependency of the regression rate. From the previous discussions, for a pressure dependency, the amount of residuals is lower. The relative value of residuals referred to the total propellant is:

$r e s_{\text {tot }}=\frac{r e s_{f}}{\varphi_{\min }+1}$

where $r e s_{\text {tot }}$ is the ratio between the fuel residual mass and the initial propellant mass. Since with this strategy the maximum residuals' penalty is generated at maximum thrust, as a compensation the optimal mixture ratio can be fixed at this 


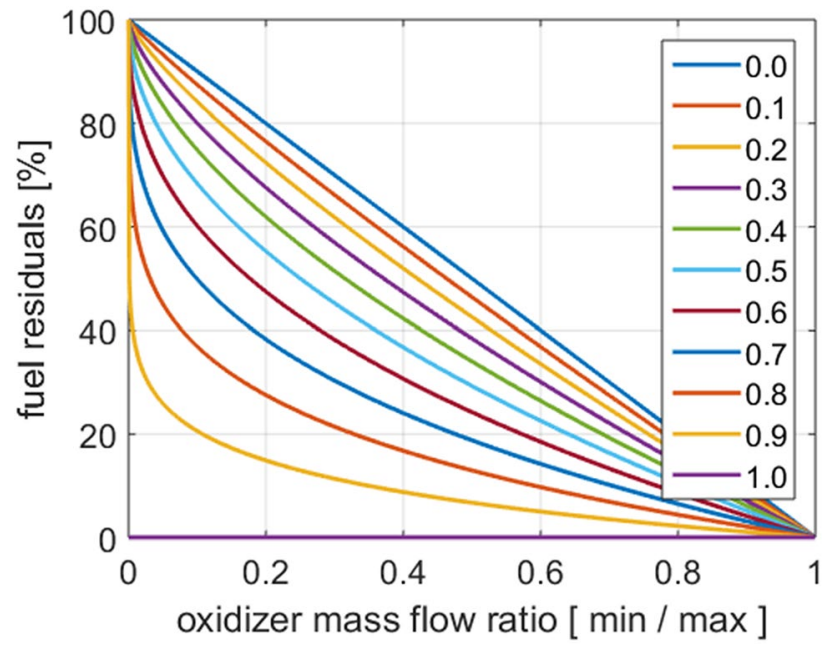

Fig. 17 Fuel residuals for different unpredicted throttling levels. Parametric with $n$

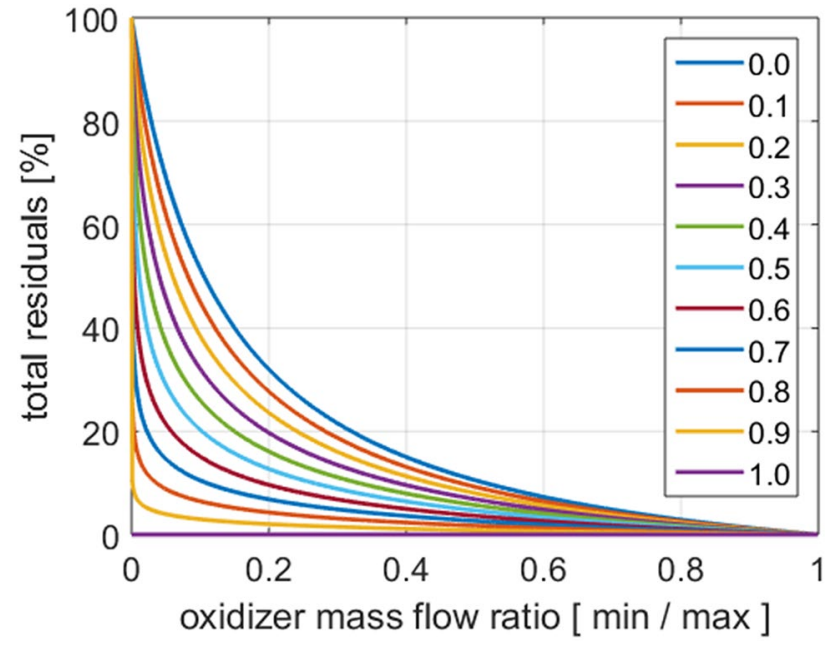

Fig. 18 Total residuals for different unpredicted throttling levels. Parametric with $n$

point. In this way the maximum thrust has only the residuals penalty while the minimum thrust has only the specific impulse penalty. The result is:

$r e s_{\mathrm{tot}}=\frac{1-\left(\frac{\dot{m}_{\text {oxmin }}}{\dot{m}_{o x \max }}\right)^{1-n}}{\left(1+\varphi_{\max }\left(\frac{\dot{m}_{o \mathrm{~min}}}{\dot{m}_{\text {ormax }}}\right)^{1-n}\right)}$

For all the intermediate levels the total impulse penalty is the combination of the specific impulse penalty and the residuals penalty.
The residuals at maximum thrust for different throttling ratios and $n$ exponents at an optimal mixture ratio of 7.5 are plotted in Figs. 17 and 18. Equation (7) is used in Fig. 17 and (9) is used in Fig. 18.

The figures show the significant penalty incurred if high throttling ratios are required but their relative duration on the total burning time is completely unknown.

However, this is an extreme situation as in most applications there is a certain degree of knowledge of the expected thrust profile. For very complex missions a statistical analysis of the possible scenarios could be performed, for example with Monte Carlo methods, to find the optimal solution that minimise the average or maximum total impulse or $\Delta V$ losses in a certain confidence interval, depending on requirements.

Anyway, a mixture ratio control becomes attractive for random high throttling ratios.

Another source of residuals is related to unexpected mixture ratio shift due to manufacturing tolerances, parameters uncertainties and motor performance variations from burn to burn [47].

However, in this case a good design including residual management and a consistent manufacturing/quality control could limit the penalty to very low values [47] and so a mixture ratio control seems not worthy.

To control the mixture ratio in real-time possible solutions include a combination of direct and indirect measurements, like oxidizer mass flows, chamber pressure, regression rate $[48,49]$ and mixture ratio [50].

\section{AOIM}

The first proposed way to control the mixture ratio in a hybrid rocket motor is the injection of part of the oxidizer in the aft-chamber. This solution requires adding a further throttleable feedline and injection system to the aft-chamber:

$\dot{m}_{\text {oxtot }}=\dot{m}_{\text {oxp }}+\dot{m}_{\text {oxaft }}$

Only the port oxidizer mass flow affects the fuel regression rate, while the other can be used for the mixture ratio compensation.

The injection in the aft-chamber presents some peculiarities respect to the one at the head-end of the motor. In fact, from one positive side the oxidizer is injected in a very hot environment, enhancing vaporisation and reactivity. On the other negative side there is less time/space for combustion to occur. The final result has to be evaluated case by case depending on design solutions, propellant combination and so on.

Compared to a classical hybrid the number of feed lines is doubled, however, the system retains some of the hybrid 
advantages compared to a liquid. Again, it can be thought as a sort of an intermediate step between the two.

A related but different technology that has also attracted some limited attention is the aft injected gas generator hybrid. In this case the oxidizer is injected on the exhausts of a throttleable solid propellant fuel-rich gas generator [51].

It is interesting to calculate the amount of oxidizer to be injected both in front and to the rear of the motor for different throttling levels, see Figs. 19, 20. To do so, (1), (2), (3) with a constant port area and variable port oxidizer flow have been used together with (4) and (10), imposing $\varphi$ as fixed.

As the port oxidizer mass flow is reduced, the fuel mass flow remains slightly higher due to the $1-n$ shift in the port mixture ratio. To keep the global mixture ratio at the optimal value, some oxidizer has to be injected in the aft-chamber. The final result is that the total mass flow decrease is lower than the port one.

In particular, for $n=0.5$, i.e. $1-n=0.5$, the thrust variation is only the square root of the oxidizer mass flow variation in the port. Consequently, to obtain a certain throttling ratio, the oxidizer mass flow in the port has to be throttled by the second power of the target throttling ratio, for example 1:25 for a 1:5 global result.

It is also worth noting that, as the motor is throttled down, the mass flow in the aft chamber has to be initially increased, then reaches a maximum value and finally starts to drop as the aft-injected oxidizer mass flow approaches the total one. For $n=0.5$ the maximum aft-chamber oxidizer mass flow for throttling is $25 \%$ of the total one. This means that while a classical hybrid needs an injector plate sized for $100 \%$ of the mass flow, in the full-throttleable AOIM case there are two injection plates, one sized for $100 \%$ of the mass flow

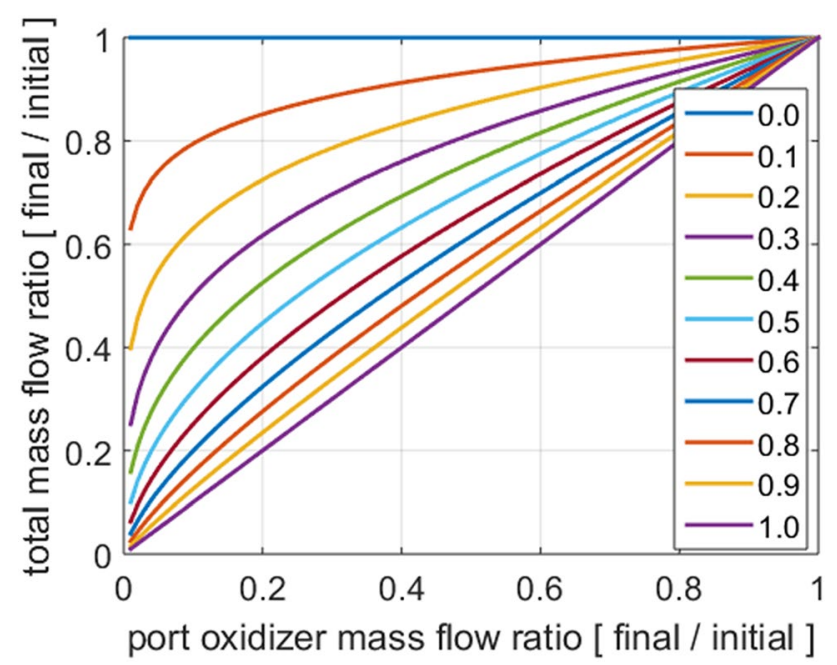

Fig. 19 AOIM total throttling ratio for different port throttling levels. Parametric with $n$

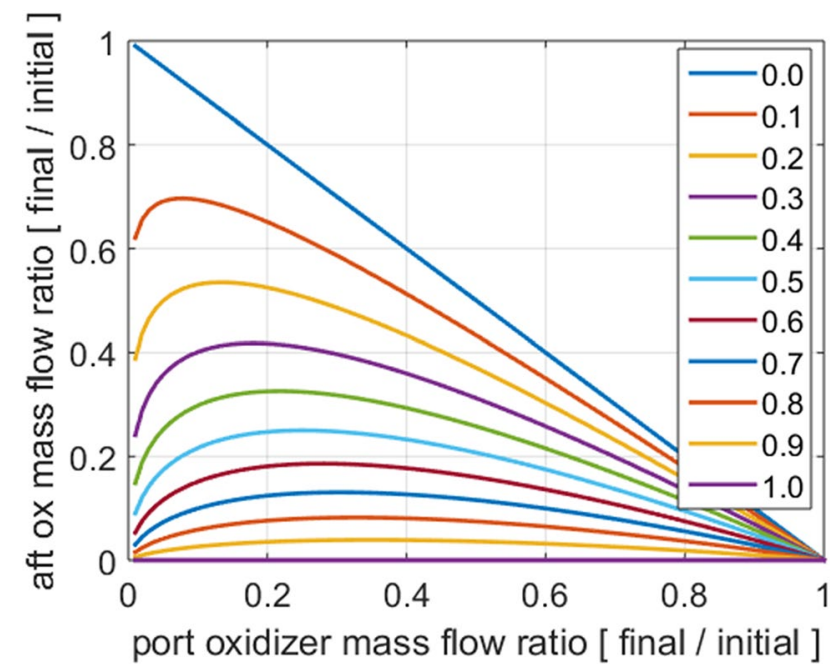

Fig. 20 AOIM aft injection for different port throttling levels. Parametric with $n$

and the other for $25 \%$. This confirms again that the positive features of the AOIM solution do not come for free in terms of weight and costs. As the value of $n$ approaches zero the technique becomes unfeasible.

In case of a pressure dependency the results improve because the mixture ratio shift in the port is reduced, see Figs. 21, 22. The AOIM can be used also to compensate the mixture ratio shift with time, see Figs. 23, 24, 25, 26, 27, 28.

To calculate the required forward and rear oxidizer mass flows, this time (1), (2), (3) have been used together with (4) and (10), imposing $\varphi$ and the total mass flow as fixed while varying the diameter and consequently the port area of the cylindrical port.

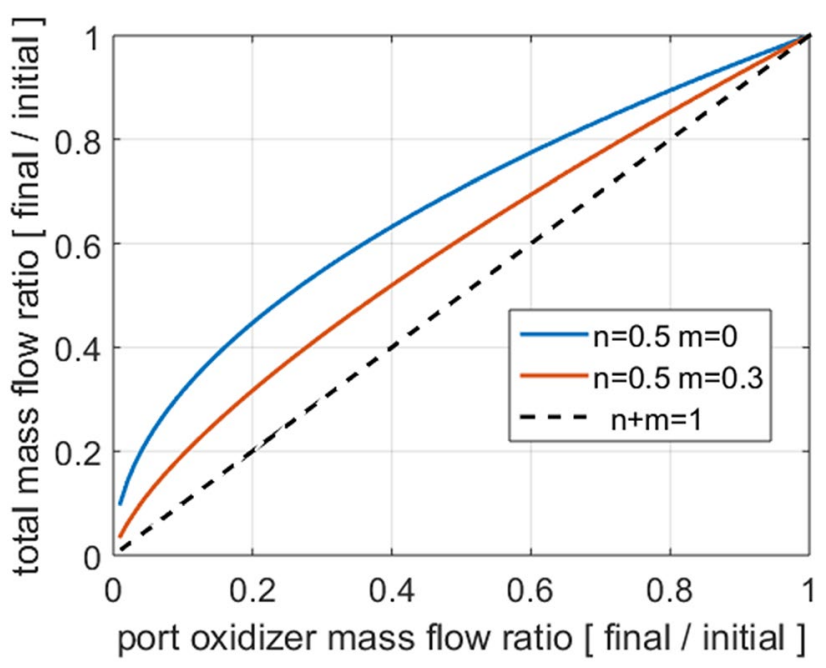

Fig. 21 AOIM total throttling ratio for different pressure dependencies 


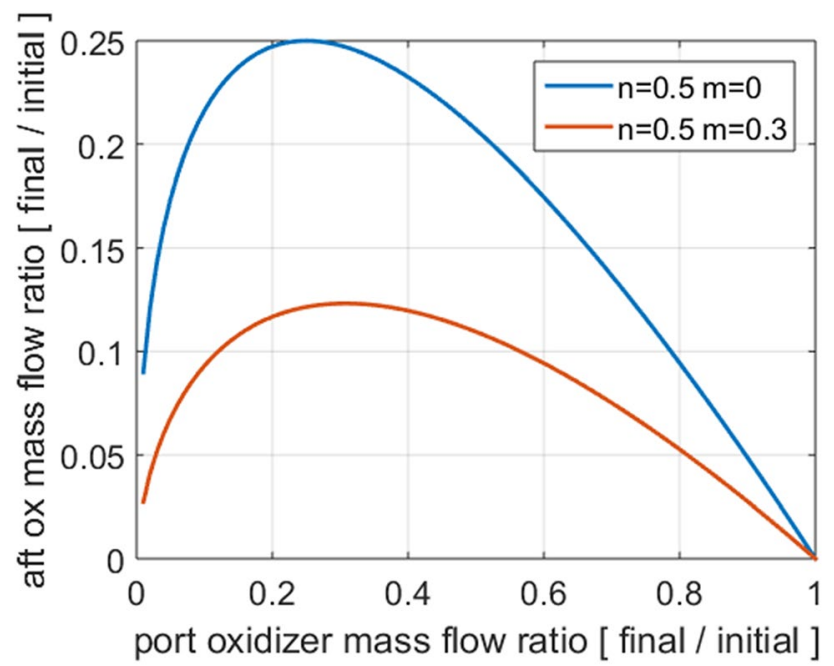

Fig. 22 AOIM aft injection for different pressure dependencies

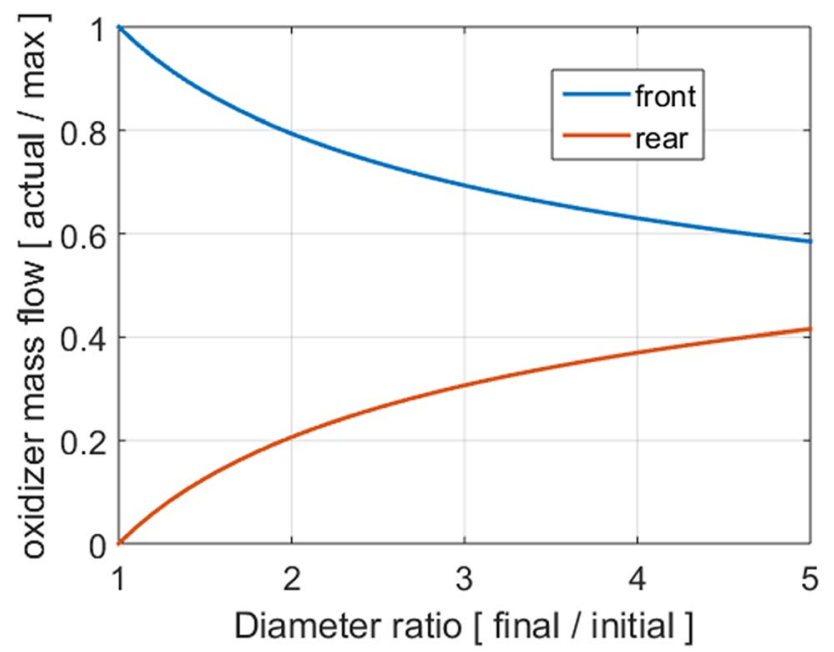

Fig. 23 AOIM oxidizer mass flows for constant mixture ratio with time, $n=0.4$

For $n<0.5$ the port oxidizer flow has to decrease to reduce the upshift of fuel mass flow. Meanwhile, for compensation, further oxidizer needs to be injected in the post chamber.

On the opposite, for $n>0.5$ the port oxidizer flow has to increase to reduce the downshift of fuel mass flow. Meanwhile, for compensation, the oxidizer injected in the post chamber needs to be reduced.

As the diameter ratio increases and/or $n$ depart from 0.5 , both feed-systems tend to require to be sized for the full mass flow.

The port mixture ratio varies always in the same way as in the classical hybrid with an amplification due to the required counter-throttling. For this reason, while the

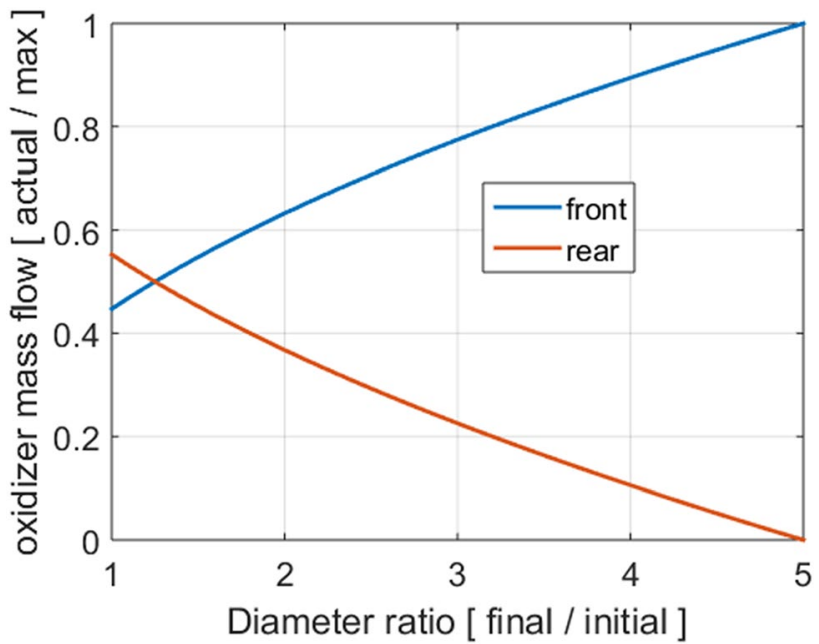

Fig. 24 AOIM oxidizer mass flows for constant mixture ratio with time, $n=0.6$

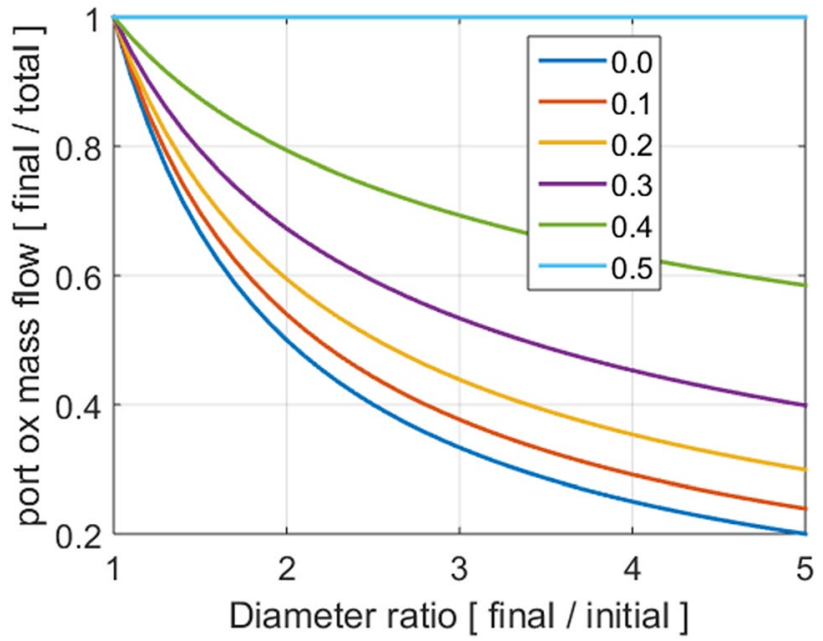

Fig. 25 AOIM forward injection for constant mixture ratio with time, parametric with $n \leq 0.5$

mathematical modelling could work, it is always important to keep in mind that too large variations of the port mixture ratio could affect combustion efficiency and grain consumption uniformity.

Moreover, both rear and forward injection systems need to work properly in a wider and wider range as the diameter ratio increases and/or $n$ depart from 0.5 .

Finally, it is important to remember that the port oxidizer mass flow must be bounded between specific limits [44].

Concluding, while the AOIM has the capability to avoid the troublesome mixture ratio shift, it requires a more complex plumbing and design and cannot be stretched to the limits, i.e. too high throttling ratios at low $n$ or too large diameter ratios for $n$ far from 0.5 . 


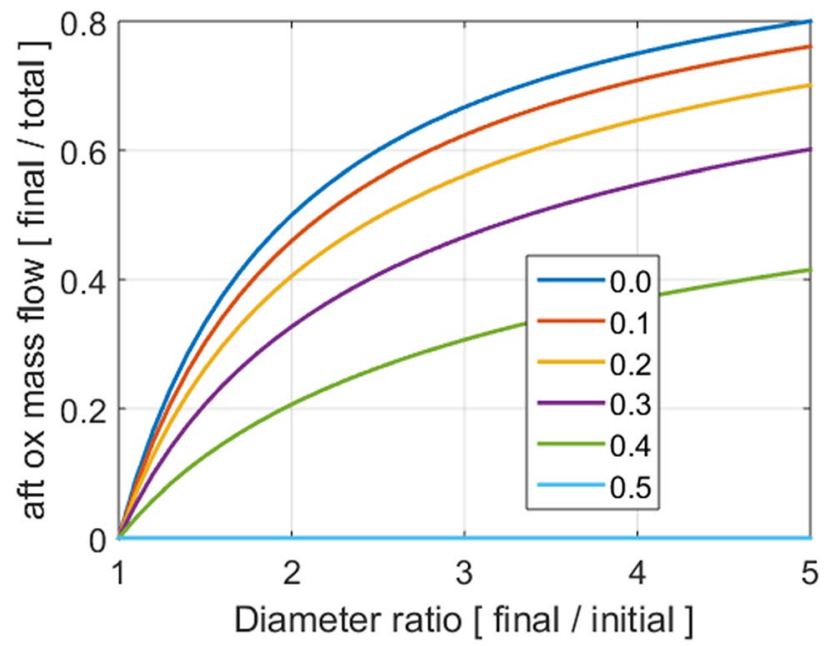

Fig. 26 AOIM aft injection for constant mixture ratio with time, parametric with $n \leq 0.5$

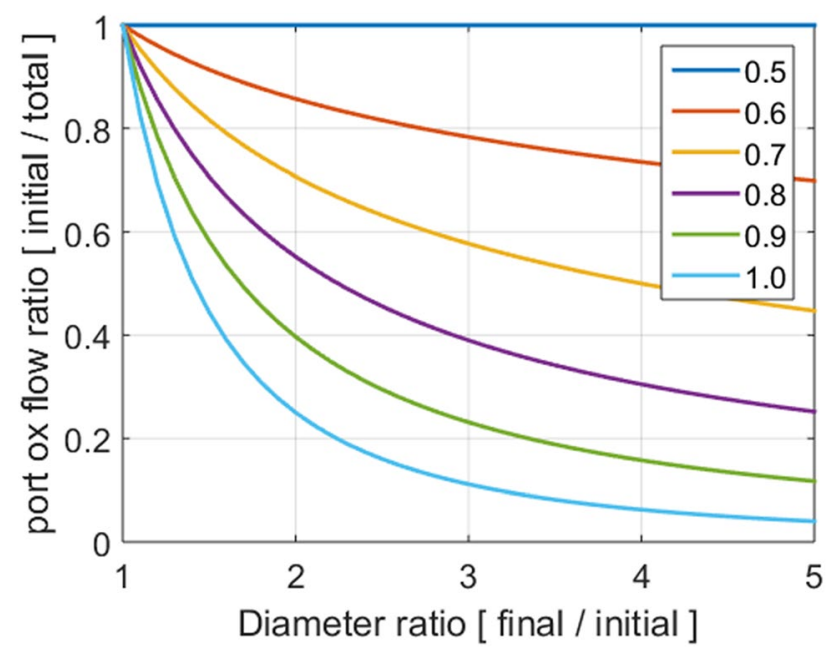

Fig. 27 AOIM forward injection for constant mixture ratio with time, parametric with $n \geq 0.5$

It is interesting also to investigate what happen if, to simplify the system, the AOIM is employed with only one throttleable feedline, the other providing a constant mass flow.

If the controlled valve is the rear one, it is easy to determine that the behaviour with throttling is the same as a classical hybrid with $n=0$, no matter the $n$ of the fuel as the front oxidizer flow is constant, so it is not useful.

On the contrary if the controlled valve is the forward one, it is possible to demonstrate that the mixture ratio shift is reduced, and as the front oxidizer mass flow reaches a lower threshold a reversal occurs, see Fig. 29.

In this case (1), (2), (3) with a constant port area and variable port oxidizer flow have been used together with (4) and (10), imposing the aft-injected oxidizer flow as fixed. As the port oxidizer flow is reduced, also the fuel mass flow

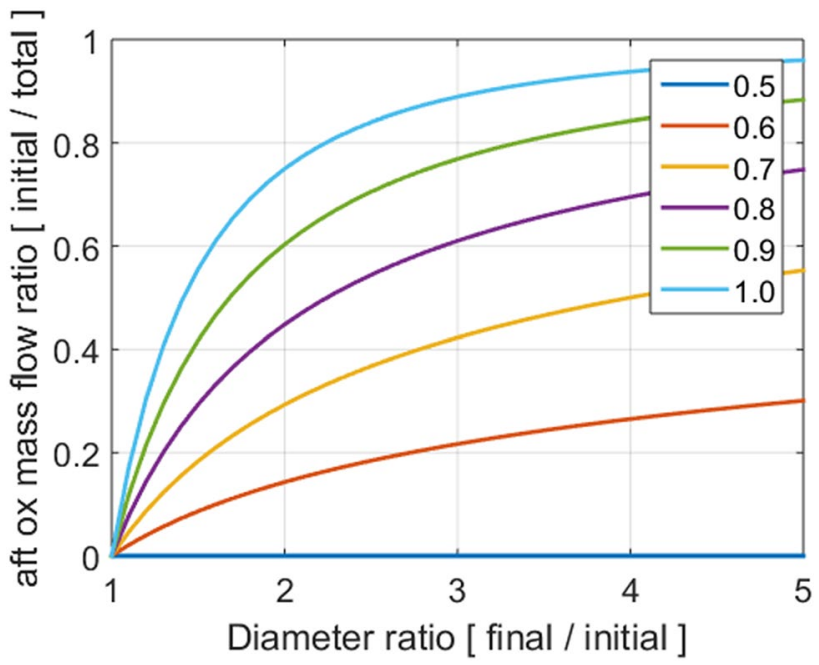

Fig. 28 AOIM aft injection for constant mixture ratio with time, parametric with $n \geq 0.5$

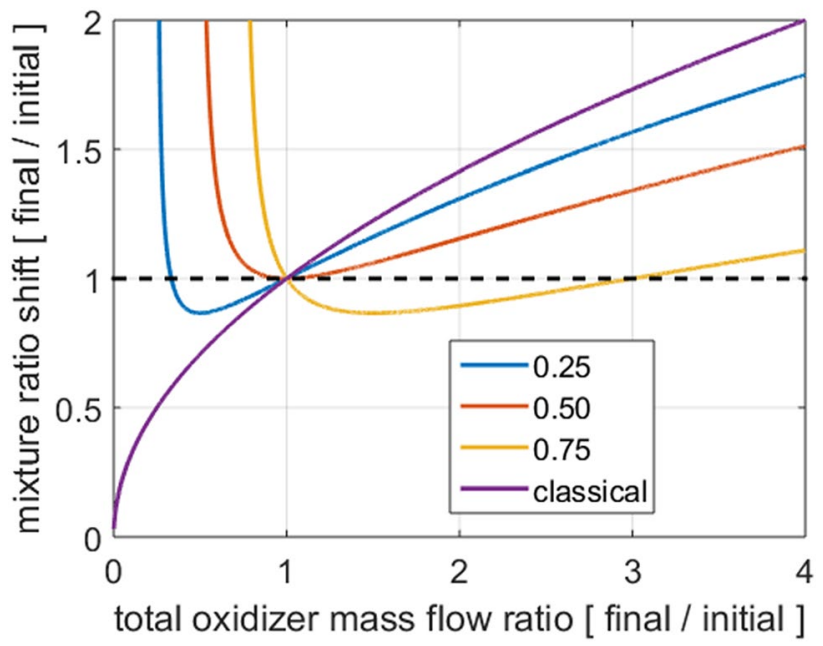

Fig. 29 AOIM with only forward injection throttling. Parametric with initial ratio between rear and front oxidizer mass flow; $n=0.5$

decreases. Since the fuel reduction is sublinear, in a classical hybrid the mixture ratio goes down. In this case, on the contrary, at a certain point the mixture ratio is dominated by the ratio of the constant rear oxidizer flow divided by the decreasing fuel mass flow, and so the mixture ratio starts to go up. So, for moderate throttling levels, this could also be considered as an option in-between a classical hybrid and a full AOIM. As in the full AOIM also in this case there is a reduction of sensitivity or gain between the input frontal oxidizer throttling and the output thrust variation.

Regarding the mixture ratio shift with time, it is interesting to calculate what is the required thrust variation to maintain a constant mixture ratio, i.e. when the mixture ratio shift with throttling is used to compensate the shift with 


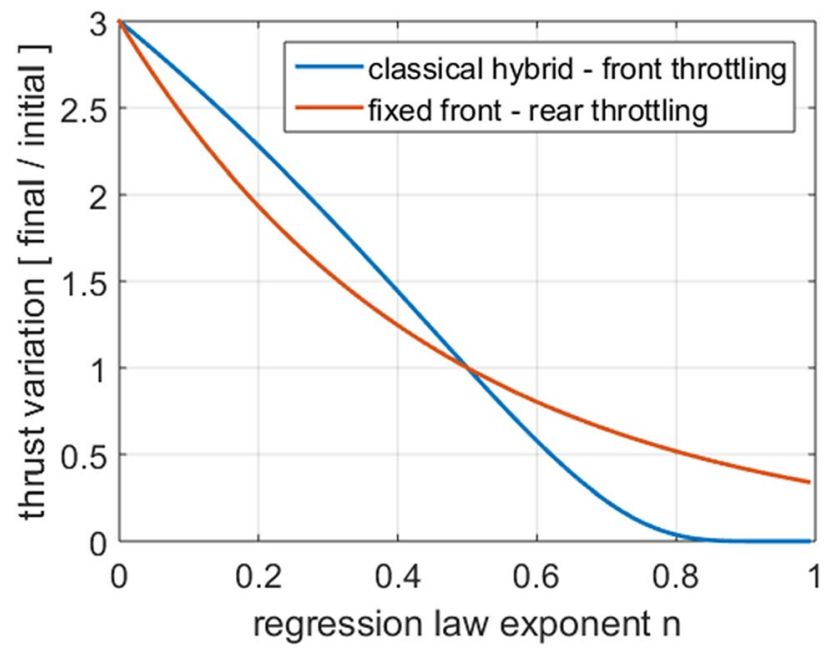

Fig. 30 Thrust variations for constant mixture ratio: classical hybrid vs AOIM with only rear injection throttling. Diameter ratio $=3$

time. The results for a classical hybrid and the AOIM with only aft-throttling are shown in Fig. 30.

For the classical hybrid with no aft-injection, (1), (2), (3) and (4) have been used imposing $\varphi$ as fixed while varying the diameter and consequently the port area of the cylindrical port. As output of the system of equations the port oxidizer flow and consequently, the total mass flow is obtained.

For the AOIM with fixed frontal oxidizer flow and rear throttling, (1), (2), (3) and (4) have been used imposing $\varphi$ as fixed while varying the diameter and consequently the port area of the cylindrical port. As output of the system of equations the rear oxidizer flow and consequently, the total mas flow is obtained.

In a classical hybrid for $n<0.5$ the fuel mass flow increases with time. To keep the mixture ratio constant, it is necessary to throttle up. This behaviour has little practical application. On the contrary for $n>0.5$ the fuel mass flow decreases with time and so, to keep the mixture ratio constant, it is necessary to throttle down.

For $n$ moderately above 0.5 , a decreasing thrust profile could have some practical application, for example in sounding rockets [52]. Obviously, for $n$ approaching 1, i.e. throttling insensitivity, the solution collapses.

The AOIM with only aft-throttling has a similar behaviour but is able to keep the mixture ratio constant with a lower thrust variation or higher $n$ and/or higher diameter ratio.

In both cases a pressure dependency, for example for metal addition, will worsen the results as the throttling sensitivity is reduced as $n+m$ approaches 1 .

The AOIM with only forward-throttling has a very complex nonlinear behaviour with regions of multiple solutions and regions of no-solutions. Even if the results are fascinating mathematically, they are of little practical value, so, for the sake of brevity, they are not reported here except for one case to mention. For $n<0.5$ but near to it and an important initial aft-injected oxidizer mass fraction, the mixture ratio can be kept constant with a moderately regressive thrust profile.

\section{A-SOFT}

Another alternative way to control the mixture ratio in a hybrid rocket motor has been proposed by Shimada et al. [38-43] and is called A-SOFT. The basic idea is that the mixture ratio shift can be compensated acting in real time on the $a$ value of the fuel regression rate. It is now well-known that swirl injection can significantly increases hybrid regression rate [53-59]. So, if the injection swirl number can be changed on demand, the regression rate can be adjusted to maintain a constant mixture ratio with time and/or throttling.

To accomplish this, again, two throttleable feed systems are required, this time both placed in the forward end of the motor, one axial and the other swirled:

$\dot{m}_{\text {oxtot }}=\dot{m}_{\text {oxp }}=\dot{m}_{\text {oxax }}+\dot{m}_{\text {oxtan }}$

Balancing the amount of axial vs swirl injected oxidizer mass flow is potentially possible to calibrate the required value of swirl number and, consequently, regression rate.

The fuel regression rate in the A-SOFT configuration is described by the following equation [43]:

$\dot{r}=a^{\prime} G_{o x}^{n}=a\left(1+S_{e}^{2}\right)^{m} G_{o x}^{n}$

The effective swirl number is related to geometric swirl number of the tangential injector trough the ratio between the axial and tangential oxidizer mass flows:

$S_{e}=S_{g} /\left(1+\dot{m}_{\text {oxax }} / \dot{m}_{\text {oxtan }}\right)^{2}$

If only the axial injection is activated, the effective swirl number is equal to zero, on the contrary, if only the tangential injection is activated, the effective swirl number is equal to the geometric swirl number of the tangential injector. However, it is not always possible to close completely a feedline, so in general:

$0 \leq S_{\min } \leq S_{e} \leq S_{\max } \leq S_{g}$

In particular, a swirl number at least above a certain minimum threshold could be necessary to guarantee sufficient levels of combustion stability and efficiency.

For the swirl injection to be effective, at least the tangential oxidizer needs to be gasified. This requires something like a catalyst, a gas generator or a regenerative heat 
exchanger. In practice, once such device is necessary, it is generally more convenient to gasify the whole oxidizer mass flow.

The exponent $m$, not to be confused with the previous pressure dependency, determines the sensitivity of the regression rate to a change in the effective swirl number. For large swirl number the dependency tends to become proportional to $2 \mathrm{~m}$.

In [54] it was demonstrated that a good correlation based on physical basis was obtained considering $2 m \approx n$, which gave a final dependency around 0.555. In [53] and [60] a nearly linear dependency was found, i.e. $2 m \approx 1$, at least in the range of swirl numbers explored.

However, Ozawa [61] determined a much weaker dependency $2 m \approx 0.2, m \approx 0.1$.

It is worth noting that classical swirled experiments like in [53-60] used different swirl injectors from test to test, while Ozawa [61] experiments used a fixed two-feeds mixed axial/tangential injection with different relative mass flows that is more representative of a real A-SOFT.

Anyway, since the value of $m$ has a deep impact on the A-SOFT behaviour, as it will be shown in the following, it is necessary to perform further research on this aspect.

It is now worth investigating the behaviour of the A-SOFT during throttling, see Figs. 31, 32, 33, 34.

To do so, (1), (2), (3) with a constant port area have been used together with (4), (11), (12) and (13), imposing $\varphi$ as fixed, varying the axial oxidizer flow and, consequently, obtaining the variation of the tangential and total ones as a function of the effective swirl number.

In Figs. 31, 32, 33, 34 a minimum Swirl number of 2 has been fixed to guarantee good motor performance at the lowest thrust.

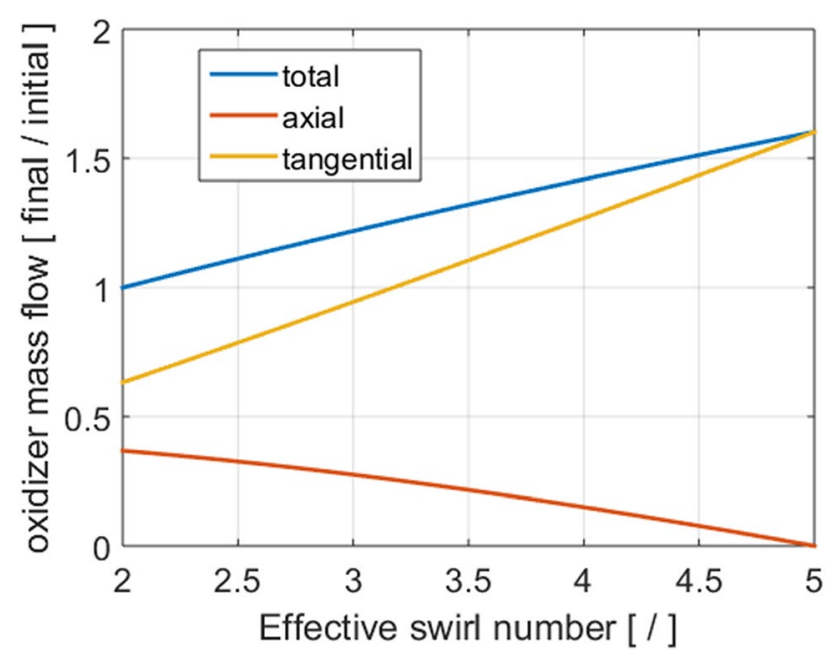

Fig. 31 A-SOFT throttling behaviour. $n=0.65 \mathrm{~m}=0.1 . S_{\min }=2$. $S_{\max }=S_{g}=5$

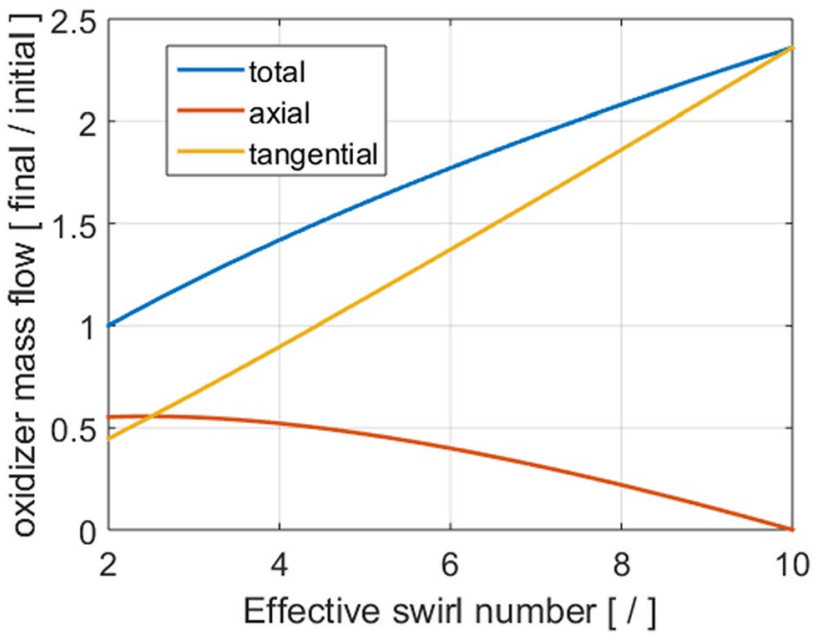

Fig. 32 A-SOFT throttling behaviour. $n=0.65 \mathrm{~m}=0.1 . S_{\min }=2$. $S_{\max }=S_{g}=10$

In Figs. 31, 32, 33 the same regression rate law as Shimada has been used, $n=0.65 \mathrm{~m}=0.1$.

In Fig. 34 the value of $m$ has been increased to 0.5 for comparison.

Since in a classical hybrid throttling up will increase the mixture ratio, in an A-SOFT it is necessary to increase the swirl number to further boost the regression rate. Consequently, throttling up is performed increasing the tangential oxidizer mass flow. At the beginning, the resulting effect is even excessive, so also the axial oxidizer mass flow has to be increased. After a certain effective swirl number, the effect weakens and so the axial mass flow has to be decreased to further boost the effective swirl number.

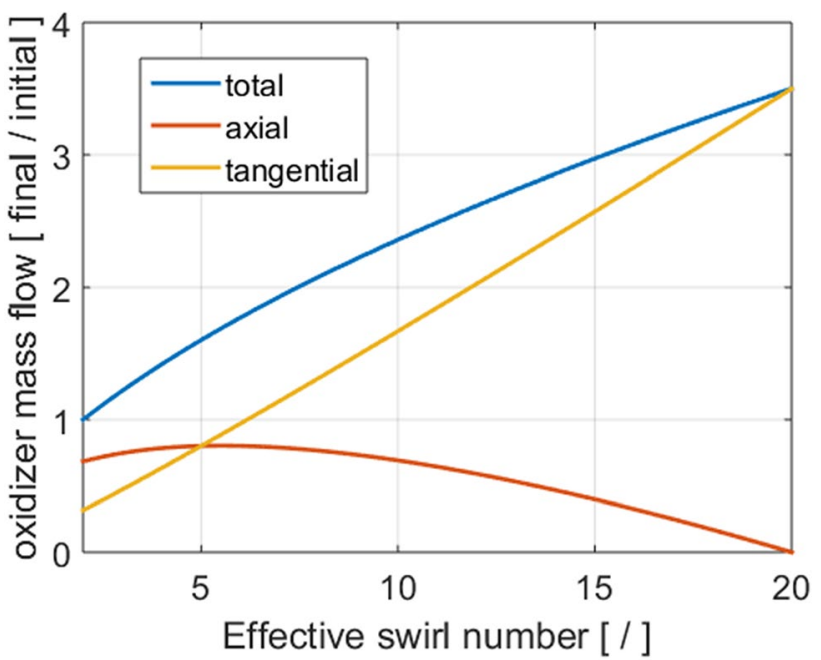

Fig. 33 A-SOFT throttling behaviour. $n=0.65 \mathrm{~m}=0.1 . S_{\min }=2$. $S_{\max }=S_{g}=20$ 


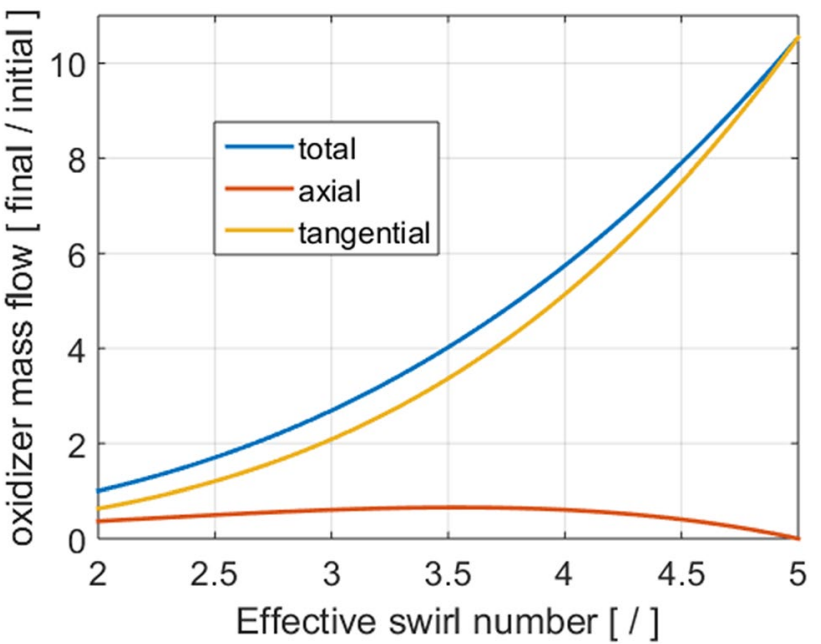

Fig. 34 A-SOFT throttling behaviour. $n=0.65 \mathrm{~m}=0.5 . S_{\min }=2$. $S_{\max }=S_{g}=5$

The point of maximum axial mass flow shifts to the left as the value of $S_{\max }$ and/or $m$ is reduced.

The maximum swirl number has been set equal to the geometric swirl number of the tangential injector, thus at maximum thrust the axial flow ceases and all the oxidizer is injected tangentially. On the opposite, at minimum thrust there is still some tangential flow as $S_{\min }>0$.

Increasing $S_{\max }$ allows to obtain higher throttling ratios. The required maximum axial mass flow is always lower than the minimum total oxidizer mass flow as it will be equal for $S_{\min }=0$.

The effect of $m$ is to increase the sensitivity to the tangential throttling, therefore with a much lower variation of swirl number it is possible to obtain significantly higher throttling ratios.

The maximum value of $S_{\max }$ is limited by several reasons. For example, increasing the swirl number has a strong influence on the reduction of the nozzle discharge coefficient and a detrimental effect on the specific impulse, the latter particularly at lower nozzle expansion ratios [62-65] and higher back pressures.

Moreover, everything else kept equal, increasing the swirl number will increase the injection velocity and therefore Mach number, requiring a higher injection pressure drop.

Both effects are significantly reduced with an increase of combustion chamber contraction ratio. Therefore, motors operating at higher chamber pressures are allowed to reach higher maximum swirl numbers.

Another aspect to consider is the increase of nozzle heat transfer/erosion with the swirl number. In fact, above the minimum threshold swirl number combustion is rather complete, so a farther increase of swirl intensity simply enhances the heat transfer and turbulent diffusion from the bulk to the wall.

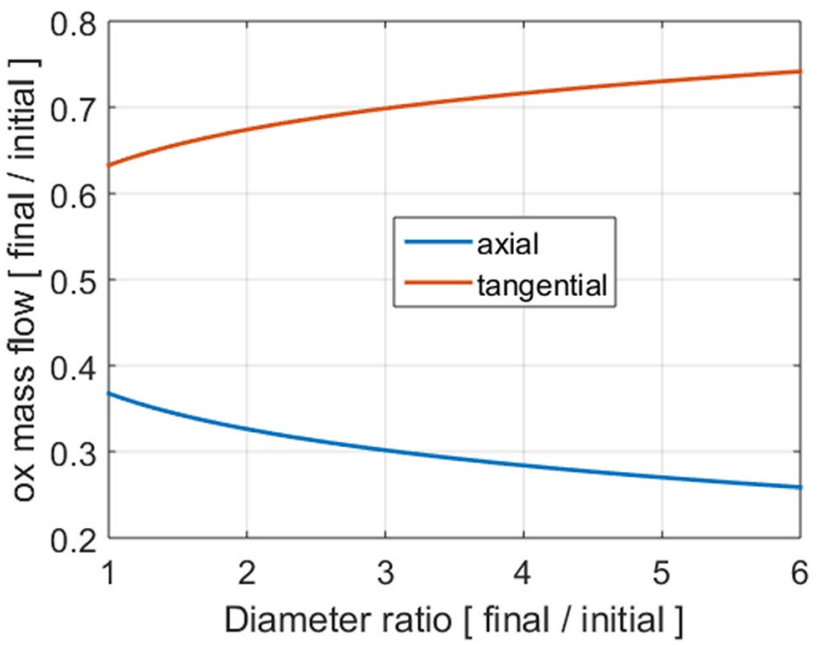

Fig. 35 A-SOFT behaviour for constant mixture ratio with time. $n=0.65 \mathrm{~m}=0.1 . S_{\min }=2 . S_{\max }=S_{g}=5$

It is now interesting to evaluate the behaviour of the A-SOFT with time, see Figs. 35, 36.

This time, (1), (2), (3) have been used together with (4), (11), (12) and (13), imposing $\varphi$ and the total mass flow as fixed, while varying the diameter and consequently the port area of the cylindrical port, obtaining as outputs the tangential and axial oxidizer mass flows.

Even with a weak swirl dependency $m=0.1$ and a small maximum swirl number of 5 the A-SOFT is able to smoothly hold constant the mixture ratio with only relatively small adjustments of the two oxidizer mass flows.

It is now interesting, again, to briefly discuss what happens if, for simplicity, only a single feedline has a throttleable valve. For throttling purposes, the feedline to control is the tangential one.

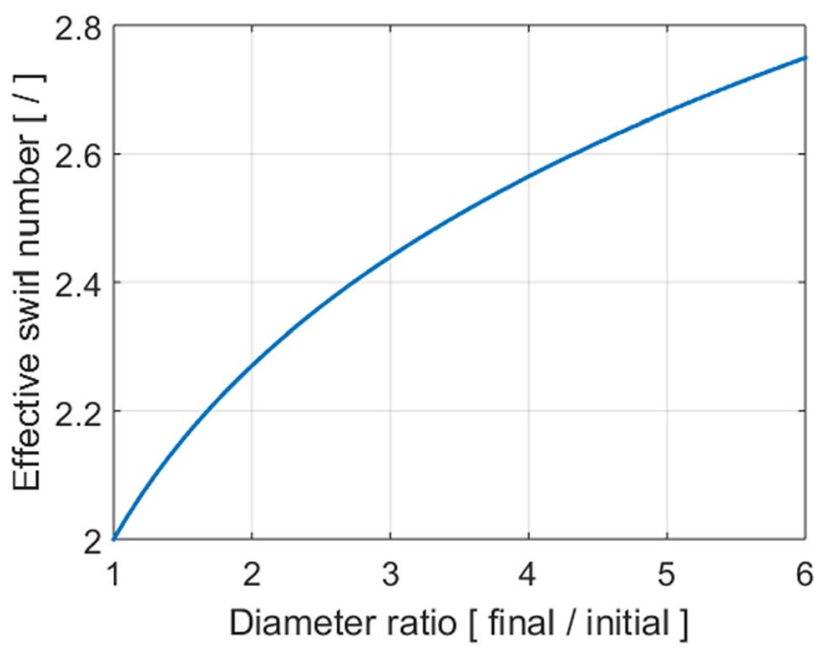

Fig. 36 A-SOFT effective swirl number for constant mixture ratio with time. $n=0.65 \mathrm{~m}=0.1 . S_{\min }=2 . S_{\max }=S_{g}=5$ 


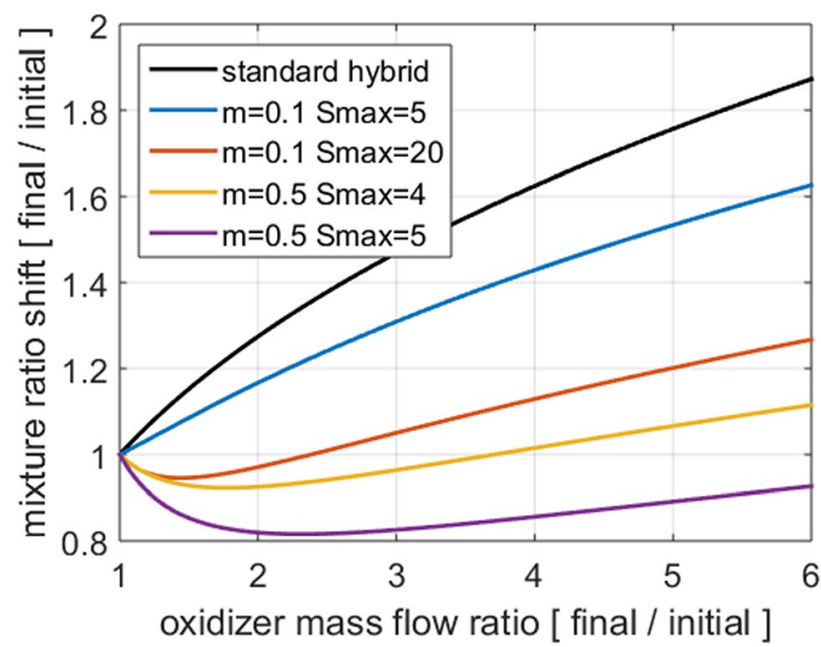

Fig. 37 A-SOFT with only tangential throttling. $n=0.65, S_{\min =} 2$

In fact, in a classical hybrid, throttling up the oxidizer flow will increase the mixture ratio. Throttling up the tangential oxidizer flow will increase the effective swirl number, boosting up the regression rate. The final results are plotted in Fig. 37.

In this case, (1), (2), (3) with a constant port area have been used together with (4), (11), (12) and (13), imposing the axial oxidizer flow as fixed and varying the tangential one, obtaining as output the fuel mass flow and, consequently, the mixture ratio variation.

The single valve A-SOFT is able to mitigate the mixture ratio shift during throttling and, for large $S_{\max }$ and/or $m$ and/ or $n$, to initially obtain the opposite trend as the increase in swirl number prevails on the standard mixture ratio shift. For specific combinations of $n, m$ and $S_{\max }$ a relatively flat behaviour can be obtained for a certain range of throttling ratios.

On the contrary, throttling only the axial feedline will behave in the opposite way, enhancing the original mixture ratio shift of the standard hybrid.

As in the general case, the opposite trend occurs considering the mixture ratio shift with time. In fact, the relatively throttling-insensitive single tangential valve A-SOFT has no possibility to effectively compensate the mixture ratio shift with time.

On the contrary, if the fuel mass flow decreases or increases with time, a relatively small decrease or increase, respectively, in the axial oxidizer flow will have two synergistic mechanisms, swirl number and throttling, for mixture ratio compensation. The final result is qualitatively similar to the standard hybrid of Fig. 30 but quantitatively better.

\section{Comparison Between AOIM and A-SOFT}

The AOIM and A-SOFT have both the potential ability to keep constant the mixture ratio during throttling and with time. Both also require two controlled feedlines and injection systems for optimum performance. However, as highlighted by the previous analyses, several differences are also present.

From an architectural point of view the AOIM requires the injection of oxidizer in the relatively far post-chamber with all its foreseen complexity and relative lack of experience in the literature. On the contrary, the two feedlines and injector plates of the A-SOFT could be better integrated in an almost single item in the front head of the hybrid motor in a similar way as in liquid engines, perhaps also exploiting additive manufacturing, with less departure from a welltested conventional swirled hybrid configuration.

The A-SOFT requires gaseous injection while the AOIM not necessarily, however, for high throttling ratios it is easy to work with gas injection even for the AOIM as in a classical hybrid due to concerns over atomisation/vaporisation.

Regarding the behaviour, previous simulations showed that the AOIM tend to be more attractive for large throttling ratios than the A-SOFT, particularly if the A-SOFT is limited in terms of $m$ and $S_{\max }$. This is a reason for the need to better investigate these two parameters in A-SOFT motors.

On the contrary the A-SOFT can deals much more easily with the mixture ratio shift with time; this is due to the fact that the port oxidizer mass flow is kept constant, while in the AOIM it is changed in the wrong direction in terms of port mixture ratio to control the fuel mass flow and needs a higher aft-injected counter-compensation.

In any case it is important to remember that the previous calculations considered the behaviour with time and throttling independently. As a throttleable motor needs still to work for a specific burning time, in practice the two effects result combined, each one using part of the allowable oxidizer feed throttling range. Therefore, in any situation, a high degree of compensation with time will reduce the margins for throttling and vice versa. That is why, again, $n=0.5$ can be in general somehow preferable also for throttling because it keeps the maximum and minimum possible thrusts constant with time.

In [43], Ozawa has drawn a graph showing the regions of applicability of the two technologies. However, the graph considered the same grain dimensions, i.e. port diameter and length. For this reason, the A-SOFT, with its possible higher regression rates operates for larger thrusts and the axial AOIM for lower thrusts. Unfortunately, in practice there is a limit in the maximum port oxidizer flux. Considering in first approximation the same port diameter and the same maximum oxidizer mass flux, the two motors can deliver 


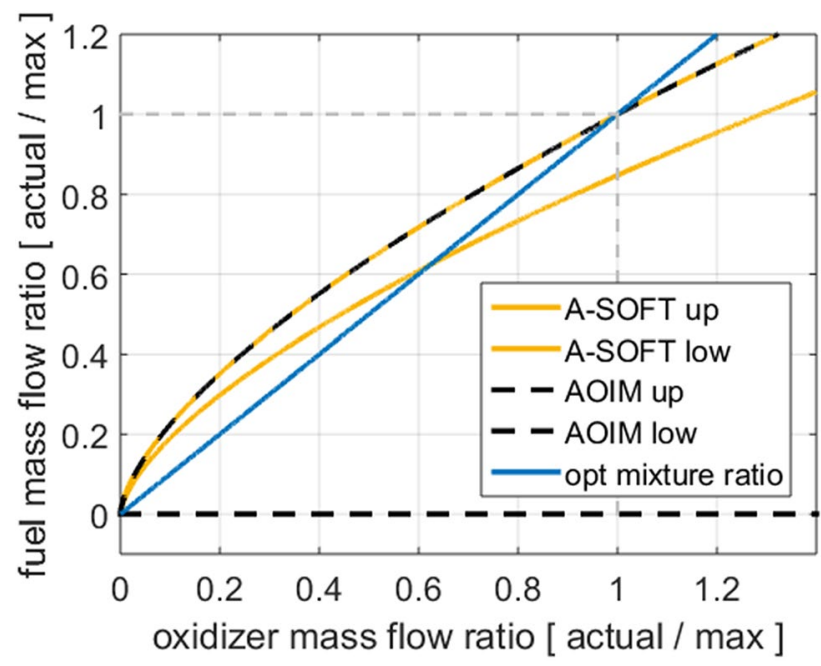

Fig. 38 A-SOFT vs AOIM. Same max oxidizer flux, different fuel grain lengths. $n=0.65, m=0.1 . S_{\min }=2 . S_{\max }=S_{g}=5$

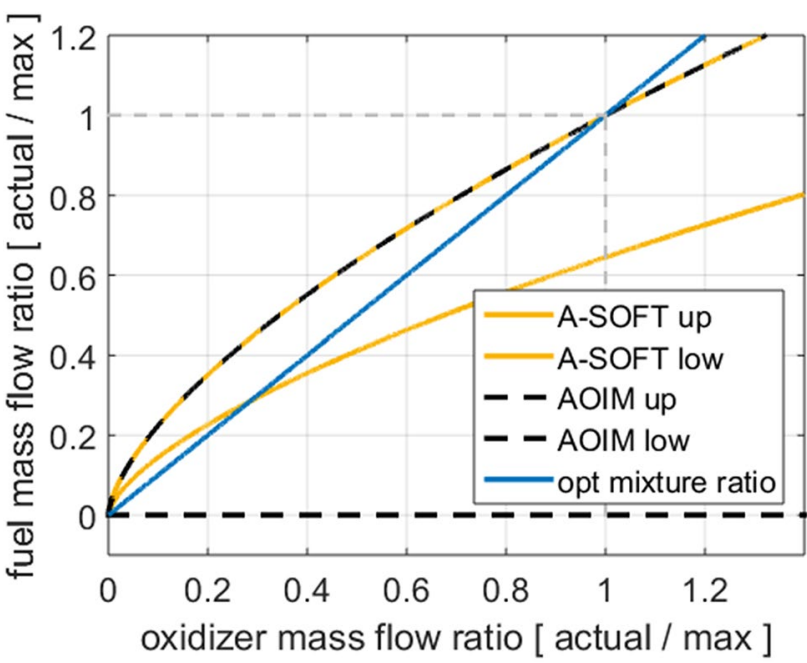

Fig. 39 A-SOFT vs AOIM. Same max oxidizer flux, different fuel grain lengths. $n=0.65, m=0.1 . S_{\min }=2 . S_{\max }=S_{g}=20$

the same maximum thrust, with the swirled one requiring a much shorter grain to keep the same mixture ratio according to the following equation:

$L_{f \mathrm{~A}-\mathrm{SOFT}}=L_{f \mathrm{AOIM}} /\left(1+S_{\max }^{2}\right)^{m}$

Modifying Ozawa figure for different grain lengths and same maximum oxidizer flux and flow the following Figs. 38, 39 are obtained.

The curves are obtained with (1), (2) for a constant area port together with (10) for the AOIM and (11), (12) and (13) for the A-SOFT.
The straight blue line represents the optimal mixture ratio, which is a fixed value, so, as the oxidizer flow is reduced, the fuel mass flow has to decrease accordingly in a linear way.

For the AOIM technology the upper curve represents the operation with only the forward injection, while for the A-SOFT it represents the operation with only the tangential injection. The lower curves represent the operation with only the rear injection and that with only the axial injection, respectively.

At maximum thrust the AOIM is operating with only the oxidizer port injection, while the A-SOFT is operating only with the tangential injection, as can be seen by the intersection with the optimal mixture ratio.

In both cases, if the oxidizer flow is reduced without the intervention of the other feedline, the motor follows the upper curve which is simply the classical sub-linear hybrid behaviour.

As expected, the fact that this curve is above the optimal mixture ratio means that with a simple one valve throttling down the hybrid motor becomes fuel rich.

Operating at the same time on both feedlines is possible to move on each point in the area between the upper and lower curves of each technology, included the target one on the straight line, i.e. optimal mixture ratio.

The result of the comparison between the two technologies shows the same upper bound for both and an extended lower bound, theoretically up to zero, for the AOIM. Obviously, as $S_{\max }$ and/or $m$ increase, the A-SOFT lower bound also approaches zero.

In [43] it is claimed that a swirled AOIM will combine both regions of operation; however, with the current hypothesis of same maximum oxidizer flux limit, the swirled AOIM will behave exactly as an axial AOIM, except for a shorter grain length and potentially better baseline combustion efficiency and stability, with better throttling and worse time behaviour compared to the A-SOFT.

It is worth noting that all the discussions up to now are based on a simplified regression rate law with constant exponents. As is well-known, in the original Marxmann theory based on forced convective heat transfer the exponent of the oxidizer flux is 0.8 [6]. However, in a complex environment such as in a hybrid rocket combustion chamber, for example, with radiation from soot particles, liquefied fuel entrainment, and/or flow characteristics such as recirculation of oxidizer flow, the index $n$ is no longer 0.8 , and can even become less than 0.5. Moreover, a simple expression with constant exponents cannot be used in a wide range of oxidizer fluxes, but generally only in a more or less restricted range, depending on the propellant combinations and motor design. For example, as shown in [6], at very high fluxes the regression rate law could be heavily influenced by chemical kinetics, particularly 
at low pressure, meanwhile radiation could become dominant at high pressures and low fluxes. Sometimes there could be even sudden changes in motor behaviour after certain thresholds, like fuel chuffing, entrainment or flame blow-out. The specific behaviour and limits can be much different depending on the propellant and configuration choices. Therefore, to develop a throttleable motor, it is necessary to deeply characterize the behavior of a specific motor baseline design at different oxidizer flow levels before applying the aforementioned concepts. However, it is expected than the results presented in this paper remain valid, at least qualitatively and as indicative trends, even for more realistic situations, perhaps considering a limited range of operating conditions or a combination of regions where the regression rate law can be fairly approximated as in (1), each time with different exponents. Anyway, for a specific motor, once a full experimental characterization of the baseline configuration has been obtained, it is not difficult to perform an almost exact numerical calculation of the predicted performance for different missions, nevertheless the discussions presented here can be a useful starting point for an initial screening.

What is important to underline is that the process of developing a highly throttleable hybrid motor is deeply connected on the particular propellant combination, the motor injection-port design and operating parameters, and even if the A-SOFT or AOIM solutions can improve the capability in a wider range, they cannot be considered as stand-alone all-around solutions.

Finally, it is worth to mention a few words on feedback control methods, control rules, and their control accuracy. This paper has been focused on the physical response of the motor to an ideal throttling input. The same tools can be used to understand the response to a real throttling input based on a defined control scheme using measurements affected by uncertainties. As pointed out in chapter 2, thanks to the tremendous advancements in sensor technology and electronic miniaturisation, today it is possible to redundantly measures directly and indirectly multiple parameters of the hybrid motor and to combine them in a complex control algorithm to maximise the accuracy and effectiveness, keeping the propulsion system always inside the appropriate boundaries and near the optimal point, as in modern full digital engines already common in the aeronautical field. Moreover, with the enormous rise in computational power on small devices it is possible to calculate the best energy management strategy in real-time as a function of the instantaneous prediction of the following but not pre-determined flight path. It is even possible to conceive that, at some point in the future, the use of artificial intelligence and machine learning can be foreseen to develop robust and optimal control software in a variety of different situations. However, even the best control system and strategy cannot overcome the physical limitations in the hardware, that is why for such applications is so important the proper selection of the propellant combination, the motor injection-port design and operating parameters with an eye on their suitability to deep throttling. Anyway, a complete discussion of feedback control methods, control rules, and their control accuracy of the hybrid motor thrust and mixture ratio will deserve a paper by its own.

\section{Other Options}

One alternative way to deal with the issues of motor throttling is to avoid the need of throttling in the first instance. For example, instead of throttling the motor, a similar effect can be achieved by a series of constant thrust pulses, a technique called Pulse Width Modulation (PWM). Compared to throttling the motor, in this case there is no mixture ratio shift, no chamber pressure and thrust coefficient reduction, no changes in the exhaust conditions, no need of complex plumbing and injection designs able to operate in a wide range. What is required is a multiple ignition capability, another possible feature of hybrid rocket motors.

One drawback is a slight specific impulse penalty related to the phases of thrust rise and decay during ignition and shutdown, respectively. Base drag increase during coast phases has also to be taken into account, together with the inability to use a thrust vector control for manoeuvres during periods of motor off. Moreover, for few pulses, a non-optimised flight profile could induce trajectory losses, while for a high number of pulses the impact of the thrust ramps/tails becomes non-negligible.

Hybrids tend to have slower transients compared to liquids of the same thrust because of the larger combustion chamber size, the thermal lag in the fuel grain and, for ignition, the generally lower reactivity of the solid fuel, thus they are not best suited for high frequency pulses.

In a hybrid rocket, throttling up and down is generally faster and precise than the complete start and stop sequence, so a throttleable motor is more favourable for precise control applications like soft-landing.

Another option is to use a cluster of smaller motors or combustion chambers and operate only a certain number of them to achieve different thrust levels. Again, no issues related to motor throttling are present, even if only certain finite thrust levels can be achieved depending on the number of motors and their relative thrusts. If the thrust levels are only descending and not separated in time, only thrust termination is required, on the contrary, if they are also upward and/or spaced in time the re-ignition capability is again necessary. 
Issues of thrust misalignment constrain the arrangement and the possible combinations of thrusters' activation in order to keep symmetry respect to the centre of mass.

For equal motors, clustering generally brings development and production advantages respect to an equivalent single larger unit at the expense of a penalty in the inert mass fraction. If the motors have different sizes more combinations of thrust levels can potentially occur for the same total number of motors at the expense of a higher system complexity.

It is important to remember that hybrid propulsion is less flexible than liquid propulsion in this regard. In fact, equal liquid motors of the same thrust can deliver different total impulses as they are fed for less or more time. On the contrary, hybrid motors are designed to deliver a certain total impulse determined by the amount of fuel placed in the combustion chamber.

A technique used in solid propulsion called off-loading could allow for a slight variation in the amount of fuel casted, but its range is limited.

Moreover, in case of unpredicted required thrust profiles, a cluster of liquid engines can always deplete all its propellants, while in a hybrid rocket the unspent fuel in a combustion chamber cannot be used by the others, limiting the flexibility of this approach.

A combination of the techniques exposed in this chapter and conventional throttling can also be foreseen to mitigate the motor throttling requirements. A typical example is the SpaceX Falcon 9 booster, which has nine slightly throttleable Merlin engines and only one is used on landing, with three used during re-entry. Moreover, the booster lands thanks to a manoeuvre called hover slam, where the thrust of the rocket is superior to the weight of the system and so, after slowdown, only careful timing of motor shutdown allows for safe touchdown. This is in contrast with Blue Origin New Shepard suborbital vehicle that requires a highly throttleable engine to perform controlled hovering before touchdown.

\section{Deep Throttling}

Other than the mixture ratio shift, hybrid throttling comes with issues in common with liquid engines, like the need to keep a high combustion efficiency and stability in a wide range of mass flows.

In particular, properly controlling the mass flow and the injection characteristics are two key elements for a throttleable system.

Regarding the first point, if the mass flow is controlled with a simple valve, a reduction of the mass flow is obtained with a significant increase of pressure losses in the feedline.
On the opposite, a proven successful technique to control the mass flow in a large range with limited pressure drop is the variable are cavitating venturi or cavitating pintle [28, 29, 66-68]. A cavitating venturi is used to decouple the mass flow from chamber pressure, with a benefit in combustion stability and ease of control. Varying the throat area through a movable pintle allows a wide variation of mass flow for the same upstream pressure.

Regarding the issue of injection performance, a decrease of the mass flow through a fixed injector will cause a reduction in the injection pressure drop, negatively affecting atomisation and injector stiffness.

The main solutions for hybrid throttling that have been considered are briefly presented in the following subsections. All of them are somewhat borrowed from liquid propulsion [69].

\subsection{Simple Fixed Geometry Injector}

The easiest way to throttle a hybrid motor is to simply vary the mass flow through a valve without any other changes. However, this option, even if attractive for its simplicity, as highlighted before, brings a reduction in the injector pressure drop with a potential loss of injection performance that could affect motor stability and efficiency, unless the initial pressure drop is very high.

Whitmore $[23,24]$ showed a remarkable 66:1 turndown ratio on a lab-scale motor using nitrous oxide as oxidizer. However, the scale of the motor was small and the injection was certainly improved by the two-phase flow of nitrous oxide and the very high pressure drop. In the general case, based also on the liquid literature, this technique is not best suited for large throttling ranges of high performing systems.

\subsection{Dual Manifold}

This technique foresees the use of multiple injector regions, generally two, that are controlled independently to partialise the oxidizer flow through the closure of one or more lines.

This solution has been tested successfully in several occasions, for example by ONERA [70, 71], UTC [10-12] and in the JIRAD program [20], reaching throttling ratio as high as $10: 1$.

An analogous technology has been developed at Stanford University for the Peregrine sounding rocket [72, 73]. A custom-made throttling plate that mates to the injector face inside the injector manifold is rotated to control the oxidizer mass flow rate between $50-100 \%$ of the nominal value.

This kind of solutions are not best suited for continuous throttling but they are particularly attractive for boost-sustain thrust profiles. In this case, in order to compensate the mixture ratio shift, an interesting idea is to use a dual concentric 
grain composed by a high regressing fuel like paraffin in the inner core and a lower regressing fuel like a classical plastic in the outer periphery in order to match the mixture ratio during both phases [74, 75].

\subsection{Gas Injection}

This technique foresees the injection of a small quantity of gas in order to increase the pressure drop and improve atomization at reduced liquid mass flows.

An evident drawback is the added complexity and weight. Moreover, if the gas is inert, it can negatively affect propulsion performance. Better results could be achieved when the system is already pressure-fed with a gaseous oxidizer that can be spilled for this purpose, for example gaseous oxygen [76].

This technique lost the competition with the pintle injector for the Lunar Module during the Apollo program. In the hybrid field it was tested by Waidmann [77]. It has been claimed that helium-injection has been also used on SpaceShipTwo RocketMotorTwo for stability reasons [78].

\subsection{Variable Area Injector}

This technique foresees the use of a movable pintle injector to guarantee good atomisation in a wide range of mass flows, even down to shut-off. This solution has been tremendously successful in liquid propulsion as demonstrated by the Moon Landings [79]. On the opposite, in the hybrid field it has been proposed sometimes [80] but little activity has been performed, particularly in regard to throttling behaviour.

\subsection{Gaseous Injection}

This technique foresees the injection of a gaseous oxidizer. In this way the problem is by-passed in advance. In fact, gaseous injection is much more robust and insensitive than liquid injection, as it naturally skips the complex steps of atomisation/vaporisation. Anyway, as the oxidizer is stored more efficiently in liquid form, this solution requires a way to gasify the oxidizer. As before, possible means to achieve this are the use of a catalyst, a gas generator or a regenerative heat exchanger. However, for the last two, the problem tends to shift upstream with the need to guarantee proper control and vaporisation at different thrust levels. Moreover, they require added hardware complexity.

The catalyst represents the simplest, most robust and versatile option. In fact, impressive results with throttling ratios up to 10:1 and complex thrust profiles, sometimes on demand in real time, have been obtained by Purdue [25], NAMMO [26, 27] and UNIPD [28-32] in simple hybrid rocket configurations with catalytically decomposed hydrogen peroxide.

\section{Conclusions}

Hybrid rockets have several possible positive features; among them, the potential ability to be deeply throttled on demand. Unfortunately, classical hybrids suffer a mixture ratio shift with both throttling and time.

Several ideas have been considered along the years to overcome these issues, playing with the propellants and/or the architecture.

The addition of energetic additives often introduces a pressure dependency in the fuel regression rate law that mitigates the shift with throttling but exacerbate the one with time.

Two main techniques have been proposed to directly control the mixture ratio in hybrid rockets, the aft-injection of oxidizer (AOIM) and the altering-intensity swirled injection (A-SOFT).

In the first case, further oxidizer is added to compensate the unbalance in the mixture ratio, while in the second, the injection swirl number is controlled to directly adjust the fuel regression rate to the required value.

Both methodologies increase the complexity of the hybrid architecture trough the need for two independent controllable feed lines and injections.

The AOIM has the largest throttling range but is more troublesome to compensate with time, while, on the contrary, the A-SOFT is more limited in throttling but is very comfortable in the compensation with time.

The A-SOFT throttling range is strongly dependent on the maximum achievable swirl number and the regression rate sensitivity to the effective swirl variation, a topic that requires further investigation.

Possible alternatives to avoid or reduce the throttling needs are the use of multiple chambers or pulse width modulation.

Several possibilities are available to achieve large throttling ratios keeping at the same time high levels of combustion efficiency and stability; among them, the use of a variable area cavitating venturi to control the oxidizer mass flow coupled with a catalyst bed to decompose the oxidizer into hot gas has shown the most promising results.

Open Access This article is licensed under a Creative Commons Attribution 4.0 International License, which permits use, sharing, adaptation, distribution and reproduction in any medium or format, as long as you give appropriate credit to the original author(s) and the source, provide a link to the Creative Commons licence, and indicate if changes were made. The images or other third party material in this article are 
included in the article's Creative Commons licence, unless indicated otherwise in a credit line to the material. If material is not included in the article's Creative Commons licence and your intended use is not permitted by statutory regulation or exceeds the permitted use, you will need to obtain permission directly from the copyright holder. To view a copy of this licence, visit http://creativecommons.org/licenses/by/4.0/.

\section{References}

1. Altman D, Holzman A (2007) Overview and history of hybrid rocket propulsion. In: Chiaverini MJ, Kuo KK (eds) Fundamentals of hybrid rocket combustion and propulsion. Progress in Astronautics and Aeronautics American Institute of Aeronautics and Astronautics, Washington

2. Ordahl DD, Rains WA (1965) Recent developments and current status of hybrid Rocket Propulsion. J Spacecr Rockets 2(6):923-926

3. Wagner KR, Schmucker RH (1992) Hybrid rockets for space transportation: a critical assessment. In: 28th AIAA/ASME/SAE/ ASEE Joint Propulsion Conference and Exhibit, Nashville, TN, USA, 6-8 July 1992; AIAA-92-3305

4. Grosse M (2007) Design challenges for a cost competitive hybrid rocket booster. In: EUCASS, 2nd European Conference for Aerospace Sciences, Brussels, Belgium, 1-6 July 2007; paper no. 07-345

5. Kuo KK, Chiaverini MJ (2007) Challenges of hybrid rocket propulsion in the $21^{\text {st }}$ century. In: Chiaverini MJ, Kuo KK (eds) Fundamentals of hybrid rocket combustion and propulsion. Progress in Astronautics and Aeronautics, American Institute of Aeronautics and Astronautics, Washington

6. Altman D, Humble R (1995) Hybrid rocket propulsion systems. In: Humble R, Henry GN, Larson WJ (eds) Space propulsion analysis and design. McGraw Hill Space Technology Series, London

7. Barato F, Bellomo N, Pavarin D (2016) Integrated approach for hybrid rocket technology development. Acta Astronaut 128:257-326

8. Whitmore SA, Merkley SL, Walker SD, Spurrier ZS (2015) Throttled launch-assist hybrid rocket motor for an Airborne NanoSat Launch Platform. In: 51st AIAA/SAE/ASEE Joint Propulsion Conference, Orlando, FL, USA

9. Moore GE, Berman K (1956) A solid-liquid rocket propellant system. Jet Propuls 26(11):965-968

10. Franklin B, Mead J, Bornhorst BR (1969) Certification tests of a hybrid propulsion system for the Sandpiper Target Missile. AFRPL-TR-69-73

11. Jones RA (1967) Hybrid propulsion system for an advanced rocket-powered target missile. Quarterly Technical Report, UTC 2220-QTR2

12. Penn CD, Branigan JE (1975) Preliminary flight rating tests of the HAST propulsion system. AFRPL-TR-15-5

13. French JR (1987) AMROC industrial launch vehicle: a low cost launch vehicle. SAE Technical Paper, London, p 871336

14. Kniffen R, McKinney B, Estey P (1990) Hybrid rocket development at the American Rocket Company. In: 26th Joint Propulsion Conference, Orlando, FL, USA, 16-18 July 1990; AIAA-90-2762

15. Estey PN, Flittie KJ (1992) Aquila: the next generation launch service for small satellites. In: 14th International Communication Satellite Systems Conference and Exhibit, Washington DC, USA, pp 22-24
16. Flittie KJ, Estey P (1993) Large-scale hybrid motor performance and designs for use in launch vehicle applications. JANNAF Propuls Meet 2:37-50

17. McFarlane JS, Kniffen RJ, Lichatowich J (1993) Design and testing of AMROC's 250,000 pound thrust hybrid motor. AIAA/ SAE/ASME/ASEE 29th Joint Propulsion Conference and Exhibit, Monterey, CA, USA, June 28-30, 1993. AIAA-93-2551

18. Flittie KJ, Estey PN, Kniffen R (1992) The aquila launch vehicle: a hybrid propulsion space booster. Acta Astronaut 28:99-110

19. Hybrid Propulsion Technology Program Final Report. NASACR-183952, 31 January 1990. Atlantic Research Corporation, Virginia Propulsion Division

20. Boardman TA, Carpenter RL, Goldberg BE, Shaeffer CW (1993) Development and testing of 11- and 24-inch hybrid motors under the joint government/industry IR\&D program. In: 29th Joint Propulsion Conference and Exhibit Monterey, CA, USA, June 28-30, 1993; AIAA-93-2552

21. Carpenter RL, Boardman TA, Claflin SE, Harwell RJ (1995) Hybrid propulsion for launch vehicle boosters: a program status update. In: 31st AIAA/ASME/SAE/ASEE Joint Propulsion Conference and Exhibit, San Diego CA, July 10-12, 1995; AIAA 95-2688

22. Arves J, Gnau M, Joiner K, Kearney D, McNeal C, Murbach M (2003) Overview of the hybrid sounding rocket (HYSR) project. In: 39th AIAA/ASME/SAE/ASEE Joint Propulsion Conference and Exhibit, Huntsville, Alabama, USA, 20-23 July 2003; AIAA 2003-5199

23. Peterson ZW (2012) Closed-Loop Precision Throttling of a Hybrid Rocket Motor, PhD thesis, Utah State University

24. Whitmore SA, Peterson ZW, Eilers SD (2014) Closed-loop precision throttling of a hybrid rocket motor. J Propul Power 30(2):325-336

25. Austin B, Heister S, Dambach E, Wernimont E, Meyer S (2010) Variable thrust, multiple start hybrid motor solutions for missile and space applications. In: 46th AIAA/SME/SAE/ASEE Joint Propulsion Conference, Nashville TN, USA, July 25-28, 2010; AIAA 2010-7121

26. Ronningen JE, Husdal J (2012) Tests results from small-scale hybrid rocket testing. Space propulsion 2012, Bordeaux, France, 7-10 May 2012; SP2012-2364847

27. Ronningen JE et al (2012) Nammo hybrid rocket propulsion TRL improvement program. In: 48th AIAA/SME/SAE/ASEE Joint Propulsion Conference, Atalanta, GA, USA, 29 July-01 August 2012; AIAA 2012-4311

28. Ruffin A, Barato F, Santi M, Paccagnella E, Bellomo N, Miste GA, Venturelli GM, Pavarin D (2017) Development of a cavitating pintle for a throttleable hybrid rocket motor. In: 7th European Conference for Aerospace Sciences EUCASS, Milan, Italy

29. Ruffin A, Santi M, Paccagnella E, Barato F, Bellomo, N, Miste GA, Venturelli GM, Pavarin D (2018) Development of a flow control valve for a throttleable hybrid rocket motor and throttling fire tests. In: 2018 Joint Propulsion Conference, Cincinnati, OH, USA, 9-11 July 2018; AIAA-2018-4664

30. Ruffin A (2018) Study and development of throttleable hybrid rocket motors. PhD Thesis, CISAS: Space Sciences, Technologies and Measurements

31. Ruffin A, Paccagnella E, Santi M, Barato F, Pavarin D (2019) Real-time deep throttling tests of a hydrogen peroxide hybrid rocket motor. AIAA Propulsion and Energy 2019 Forum, Indianapolis, IN, USA, 19-22 August 2019; AIAA 2019-4266

32. Barato F, Bellomo N, Ruffin A, Paccagnella E, Santi M, Franco M, Pavarin D (2019) Status and Achievements of the hydrogen peroxide chemical propulsion research at padua university. Italian Association of Aeronautics and Astronautics (AIDAA) XXV International Congress, Rome, Italy, 9-12 September 2019 
33. Parissenti G, Pessana M et al (2011) Throttleable hybrid engine for planetary soft landing. In: 4th European Conference for Aerospace Sciences EUCASS, Saint Petersburg

34. Pessana $M$ et al (2012) The FP7 SPARTAN program status and achievements. space propulsion 2012, 7-10 May, Bordeaux, France

35. Faenza M, Moretto F, Barato F, Bettella A, Pavarin D (2013) Numerical and experimental activities in support of the development of hybrid-rocket engines for soft-landing applications. In: 5th European Conference for Aeronautics and Space Sciences (EUCASS), Munich, Germany, 1-5 July 2013

36. Lazzarin M, Bellomo N, Faenza M, Barato F, Rondini D, Manente M, Bettella A, Pavarin D (2012) Numerical investigation of hybrid motors for the EU FP7 SPARTAN program. In: 48th AIAA/ ASME/SAE/ASEE Joint Propulsion Conference \& Exhibit, Atlanta, GA, USA 29 July - 01 August 2012; AIAA 2012-3748

37. Culver DW (1991) Comparison of forward and aft injected hybrid rocket boosters. In: Proceedings of the 27th AIAA/SAE/ASME Joint Propulsion Conference, Sacramento, CA, USA, 24-26 June 1991; AIAA 1991-2586

38. Usuki T, Shimada T (2015) Improvement on thrust profile flexibility by oxidizer-to-fuel ratio feedback control in hybrid rocket. In: Proceedings of the 66th International Astronautical Congress (IAC), Jerusalem, Israel, 12-16 October 2015.

39. Ozawa K, Usuki T, Mishima G, Kitagawa K, Yamashita M, Mizuchi M, Katakami K, Maji Y, Aso S, Tani Y, Wada Y, Shimada $\mathrm{T}$ (2016) Static burning tests on a bread board model of altering-intensity swirling-oxidizer-flow-type hybrid rocket engine. In: Proceedings of the 52nd AIAA/SAE/ASEE Joint Propulsion Conference, Salt Lake City, UT, USA, 25-27 July 2016; AIAA 2016-4964

40. Shimada T, Usuki T (2016) Conceptual study on flight demonstration of mixture-ratio-controlled throttling of hybrid rocket. In: Proceedings of the 67th International Astronautical Congress (IAC), Guadalajara, Mexico, 26-30 September 2016

41. Ozawa K, Shimada T (2015) Flight performance simulations of vertical launched sounding rockets using altering-intensity swirling-oxidizer-flow-type hybrid motors. In: Proceedings of the 51st AIAA/SAE/ASEE Joint Propulsion Conference, Orlando, FL, USA, 27-29 July 2015; AIAA 2015-3832

42. Messineo J, Kitagawa K, Shimada T (2018) O/F ratio measurement for hybrid rocket engine feedback control. In: Proceedings of the 15th International Conference on Flow Dynamics (ICFD), Sendai, Japan, pp 9-13

43. Ozawa K, Shimada T (2018) A theoretical study on throttle ranges of $\mathrm{O} / \mathrm{F}$ controllable hybrid rocket propulsion systems. J Fluid Sci Technol 13(4):JFST0031

44. Barato F, Paccagnella E, Pavarin D (2020) Explicit analytical equations for single port hybrid rocket combustion chamber sizing. J Propuls Power 36(6):869-885

45. Gordon S, McBride BJ (1994) Computer program for calculation of complex chemical equilibrium composition and application. NASA Reference Publication, Washington, p 1311

46. Shark $S$ et al (2011) Theoretical performance analysis of metal hydride fuel additives for rocket propellant applications. In: 47th AIAA/ASME/SAE/ASEE Joint Propulsion Conference and Exhibit, San Diego, CA, USA, 31 July-03 August 2011; AIAA 2011-5556

47. Barato F, Grosse M, Bettella A (2014) Hybrid rocket residuals: an overlooked topic. In: 50th AIAA/ASME/SAE/ASEE Joint Propulsion Conference and Exhibit, Cleveland, OH, USA, pp 28-30, July 2014; AIAA 2014-3753

48. Boardman T, Porter L, Brasfield F, Abel T (1995) An ultrasonic fuel regression rate measurement technique for mixture ratio control of a hybrid motor. In: 31st AIAA/SAE/ASME/ASEE Joint
Propulsion Conference and Exhibit, San Diego CA, July 10-12, AlAA 95-3081

49. Tadini P, Paravan C, Maggi F, Boiocchi M, Colombo G, De Luca LT (2013) Regression Rate Measurements in Lab-Scale Hybrid Burners. In: Proceedings of the 5th European Conference for Aeronautics and Space Sciences (EUCASS); Munich, Germany, 1-5 July 2013

50. Ewig R (2009) Reverse technology transfer, a case study: use of automotive OF sensors in rocket applications. Holder Consulting Group White Paper, Washington

51. Pilon B, Lowers J (2010) Development of staged combustion aftinjected hybrid (SCAIH) Propulsion at Cesaroni Technology Inc. In: 46th AIAA/ASME/SAE/ASEE Joint Propulsion Conference \& Exhibit, Nashville, TN, USA, 25-28 July 2010; AIAA 2010-6786

52. Barato F, Bettella A, Pavarin D (2013) Numerical investigation of pressure-fed solutions for paraffin-based hybrid rocket motors. In: 49th AIAA/ASME/SAE/ASEE Joint Propulsion Conference \& Exhibit, San Jose, CA, USA, 14-17 July 2013; AIAA 2013-3897

53. Franco M, Barato F, Paccagnella E, Santi M, Battiston A, Comazzetto A, Pavarin D (2020) Regression rate design tailoring through vortex injection in hybrid rocket motors. J Spacecr Rockets 57(2):278-290

54. Paccagnella E, Barato F, Pavarin D, Karabeyoğlu A (2017) Scaling parameters of swirling oxidizer injection in hybrid rocket motors. J Propuls Power 33(6):1378-1394

55. Bellomo N, Barato F, Faenza M, Lazzarin M, Bettella A, Pavarin D (2013) Numerical and experimental investigation of unidirectional vortex injection in hybrid rocket engines rockets. J Propuls Power 29(5): 1097-1113

56. Paccagnella E, Barato F, Pavarin D, and Karabeyoglu A (2016) Scaling of hybrid rocket motors with swirling oxidizer injectionPart 2. In: 52nd AIAA/ASME/SAE/ASEE Joint Propulsion Conference \& Exhibit, Salt Lake City, UT, USA, 25-27 July 2016; AIAA 2016-4750

57. Bellomo N, Faenza M, Barato F, Bettella A, Pavarin D (2012) The "Vortex Reloaded" project: experimental investigation on fully tangential vortex injection in N2O- paraffin hybrid motors. In: 48th AIAA/ASME/SAE/ASEE Joint Propulsion Conference \& Exhibit, Atlanta, GA, USA, 29 July-01 August 2012; AIAA 2012-4304

58. Bellomo N, Faenza M, Barato F, Bettella A, Pavarin D, Selmo A (2012) The "Vortex Reloaded" project: numerical investigation on fully tangential vortex injection in N2O- paraffin hybrid motors. In: 48th AIAA/ASME/SAE/ASEE Joint Propulsion Conference and Exhibit, Atlanta, GA, USA, 29 July-01 August 2012; AIAA 2012-3903

59. Barato F, Faenza M, Bellomo N, Lazzarin M, Bettella A, Pavarin D (2012) Numerical simulations of an $\mathrm{H} 2 \mathrm{O} 2$ vortex hybrid rocket motor. Space propulsion 2012, Bordeaux, France, 7-10 May 2012; SP2012-2394173

60. Yuasa S, Yamamoto K, Hachiya H, Kitagawa K, Oowada Y (2001) Development of a small sounding hybrid rocket with a swirling-oxidizer-type engine. In: 37th Joint Propulsion Conference and Exhibit, Salt Lake City, UT, USA, 8-11 July 2001; AIAA 2001-3537

61. Ozawa K et al (2016) Static burning tests on a bread board model of altering intensity swirling-oxidizer-flow-type hybrid rocket engine. In: 52nd AIAA/SAE/ASEE Joint Propulsion Conference, Salt Lake City, UT, USA, July 25-27, 2016; AIAA 2016-4964

62. Mager A (1961) Approximate solution of isentropic swirling flow through a nozzle. ARS J 31(8):1140-1148

63. Cutler AD, Barnwell RW (1999) Vortex flow in a convergentdivergent nozzle. AIAA J 37(10):1329-1331

64. Gany A, Mor M, Goldman C (2005) Analysis and characteristics of chocked swirling nozzle flows. AIAA J 43(10):2177-2181 
65. Abdelhafez A, Gupta AK (2010) Swirling airflow through a nozzle: choking criteria. J Propuls Power 26(4):754-764

66. Tian H, Zeng P, Yu N, Cai G (2014) Application of variable area cavitating venturi as a dynamic flow controller. Flow Meas Instrum 38:21-26

67. Sheng Z, Cai G, Tian H, Yu N, Zeng P (2015) Experimental tests of throttleable $\mathrm{H} 2 \mathrm{O} 2 / \mathrm{PE}$ hybrids. In: 51st AIAA/SAE/ASEE Joint Propulsion Conference, Orlando, FL, USA, 27-29 July 2015; AIAA 2015-3831

68. Faenza M, Moretto F, Tijsterman R, Popela R, Dvorak, P, Petronio D, Pavarin D (2014) Experimental characterization of a cavitating pintle valve with $\mathrm{H} 2 \mathrm{O} 2$. In: 4th AAF/ESA/CNES Space Propulsion Conference, Cologne, Germany

69. Casiano MJ et al (2010) Liquid-propellant rocket engine throttling: a comprehensive review. J Propuls Power 26(5):897-923

70. Duban P (1968) The "LEX" rocket probe (LEX small rocket probe for in-flight testing of ONERA studies of hybrid propulsion, discussing design and program). L'Aeronautique et L'Astronautique 2:47-54

71. Calabro M (2011) Overview on hybrid propulsion. Prog Propuls Phys 2:353-374

72. Dyer J, Doran E, Dunn Z, Lohner K, Bayart C, Sadhwani A, Zilliac G, Cantwell PB, Karabeyoglu A (2007) Design and development of a $100 \mathrm{~km}$ nitrous oxide/paraffin hybrid rocket vehicle. In: 43rd AIAA/ASME/SAE/ASEE Joint Propulsion Conference amd Exhibit, Cincinnati, Ohio, USA, 8-11 July 2007; AIAA 2007-5362

73. Doran E, Dyer J, Marzona MT, Karabeyoglu A, Zilliac G, Mosher R, Cantwell B (2009) Status Update Report or the Peregrine
Sounding Rocket Project: Part III. In: 45th AIAA/ASME/SAE/ ASEE Joint Propulsion Conference and Exhibit, Denver, Colorado, USA, 2-5 August 2009; AIAA 2009-4840

74. Barato F, Ghilardi M, Santi M, Pavarin D (2016) Numerical optimization of hybrid sounding rockets trough coupled motortrajectory simulation. In: 52nd AIAA/ASME/SAE/ASEE Joint Propulsion Conference and Exhibit, Salt Lake City, UT, USA, 25-27 July 2016; AIAA 2016-4749

75. Boronowsky KM (2011) Non-homogeneous hybrid Rocket Fuel for Enhanced Regression Rates Utilizing Partial Entrainment. Master's Thesis, San Jose state University

76. Karabeyoglu A, Stevens J, Geyzel D, Cantwell B (2011) High performance hybrid upper stage motor. In: 47th AIAA/ASME/ SAE/ASEE Joint Propulsion Conference and Exhibit, San Diego, CA, USA, 31 July-03 August 2011; AIAA-2011-6025

77. Waidmann W (1988) Thrust modulation in hybrid rocket engines. J Propuls Power 4(5):421-427

78. Messier D (2015) Virgin galactic spins its way back to rubber engine for spaceshiptwo. http://www.parabolicarc.com/2015/10/ 20/virgin-galactic-spins-rubber-engine-spaceshiptwo/. Accessed 31 Aug 2020. Parabolic Arc, 20 Oct 2015

79. Dressler GA, Bauer JM (2000) TRW pintle Engine Heritage And Performance Characteristics. In: 36th AIAA/ASME/SAE/ASEE Joint Propulsion Conference and Exhibit, Las Vegas, NV, USA, 2000; AIAA 2000-3871

80. Chen YS (2013) N2O-HTPB Hybrid rocket combustion modeling with mixing enhancement designs. In: 49th AIAA/ASME/SAE/ ASEE Joint Propulsion Conference and Exhibit, San Jose, CA, USA, 14-17 July 2013; AIAA-2013-3645 